\title{
Diagnostic accuracy of magnetic resonance imaging in detecting the severity of abnormal invasive placenta: a systematic review and meta-analysis
}

\author{
ALESSANDRA FAMILIARI ${ }^{1}$, MARCO LIBERATI ${ }^{2}$, PHILIP LIM $^{3}$, GIORGIO PAGANI ${ }^{4}$, GIUSEPPE CALI ${ }^{5}$, \\ DANILO BUCA ${ }^{2}$, LAMBERTO MANZOLI ${ }^{6}$, MARIA E. FLACCO ${ }^{7}$, GIOVANNI SCAMBIA $^{1}$ \& \\ FRANCESCO D'ANTONIO ${ }^{8,9}$ \\ ${ }^{1}$ Department of Obstetrics and Gynecology, Catholic University of The Sacred Heart, Fondazione Policlinico A. Gemelli, \\ Rome, ${ }^{2}$ Department of Obstetrics and Gynecology, University of Chieti, Chieti, Italy, ${ }^{3}$ Department of Radiology, Abington \\ Hospital, Abington, PA, USA, ${ }^{4}$ Department of Obstetrics and Gynecology, Fondazione Poliambulanza, Brescia, ${ }^{5}$ Depart- \\ ment of Obstetrics and Gynecology, Arnas Civico Hospital, Palermo, ${ }^{6}$ Department of Medical Sciences, University of \\ Ferrara, Ferrara, ${ }^{7}$ Local Health Unit of Pescara, Pescara, Italy, ${ }^{8}$ Department of Obstetrics and Gynecology, University Hospi- \\ tal of Northern Norway, Tromsø, and ${ }^{9}$ Women's Health and Perinatology Research Group, Department of Clinical Medi- \\ cine, Faculty of Health Sciences, UiT-The Arctic University of Norway, Tromsø, Norway
}

\section{Key words}

Abnormally invasive placenta, placenta accreta, increta, percreta, prenatal diagnosis, magnetic resonance imaging

\section{Correspondence}

Francesco D'Antonio, Department of Clinical Medicine, Faculty of Health Sciences, UiT The Arctic University of Norway, Hansine Hansens veg 18, 9019 Tromsø, Norway. E-mail: francesco.dantonio@uit.no

\section{Conflict of interest}

The authors have stated explicitly that there are no conflicts of interest in connection with this article.

Please cite this article as: Familiari $A$, Liberati M, Lim P, Pagani G, Cali G, Buca D, et al. Diagnostic accuracy of magnetic resonance imaging in detecting the severity of abnormal invasive placenta: a systematic review and meta-analysis. Acta Obstet Gynecol Scand 2018; 97:507-520.

Received: 25 September 2017

Accepted: 1 November 2017

DOI: 10.1111/aogs.13258

\begin{abstract}
Introduction. Accurate prenatal diagnosis of abnormally invasive placenta (AIP) is fundamental because it significantly reduces maternal morbidities. Material and methods. Medline, Embase, CINAHL and the Cochrane databases were searched. The primary aim of the present review was to elucidate the diagnostic accuracy of prenatal magnetic resonance imaging (MRI) in recognizing the severity of AIP, defined as the depth and topography of invasion. The secondary aim was to ascertain the strength of association between each MRI sign and the depth of placental invasion and to test their individual predictive accuracy in detecting such invasion. Inclusion criteria were studies on women who had prenatal MRI for ultrasound suspicion or the presence of clinical risk factors for AIP. Estimates of sensitivity, specificity, positive and negative likelihood ratios and diagnostic odds ratio were calculated using the hierarchical summary receiver characteristics curve model, and individual data random-effect logistic regression was used to calculate OR. Results. Twenty studies (1080 pregnancies undergoing MRI mainly for the ultrasound suspicion of AIP) were included. MRI showed a sensitivity of 94.4\% [95\% confidence interval (CI) 15.8-99.9], 100\% (95\% CI 75.3-100) and $86.5 \%$ (95\% CI 74.2-94.4) for detection of placenta accreta, increta and percreta, respectively; the corresponding values for specificity were $98.8 \%$ (95\% CI 70.7-100), 97.3\% (95\% CI 93.3-99.3), 96.8\% (95\% CI 93.5-98.7). MRI identified $100 \%$ of cases with S1 and $100 \%$ of those with S2 invasion confirmed at surgery. Among the different MRI signs, intra-placental dark bands showed the best sensitivity for the detection of placenta accreta, increta and percreta; as well as abnormal intra-placental vascularity, uterine bulging was associated with a higher risk of increta and percreta, exophitic mass and bladder tenting with placenta percreta. Conclusion. Prenatal MRI has an excellent diagnostic accuracy in identifying the depth and the topography of placental invasion. However, these findings come mainly from studies in which MRI was performed as a secondary imaging tool in women already screened for AIP on ultrasound and might not reflect its actual diagnostic performance in detecting the severity of these disorders.
\end{abstract}




\begin{abstract}
Abbreviations: AIP, abnormally invasive placenta; DOR, diagnostic odds ratio; HSROC, hierarchical summary receiver characteristics curve; $\mathrm{LR}^{+}$, positive likelihood ratio; $\mathrm{LR}^{-}$, negative likelihood ratio; MRI, magnetic resonance imaging; QUADAS-2, quality assessment of diagnostic accuracy studies 2; SSFP, steady-state free precession; SSFSE, single-shot fast-spin echo.
\end{abstract}

\section{Introduction}

Rises in the cesarean section rate over the last three decades have led to a massive increase in the prevalence of abnormal invasive placenta (AIP) (1-5). Accurate prenatal diagnosis of AIP is fundamental because it has been shown to reduce significantly the burden of maternal morbidities associated with such anomalies, such as lifethreatening hemorrhage, need for blood transfusion, damage to adjacent organs and admission to intensive care unit, by allowing a pre-planned management of these conditions $(6,7)$.

Ultrasound is the primary tool to diagnose AIP in women at risk, such as those with placenta previa and a prior cesarean section, whereas prenatal magnetic resonance imaging (MRI) is usually reserved for cases with inconclusive ultrasound assessment. Overall, ultrasound and MRI have a good diagnostic performance in detecting AIP, although a high variability in the diagnostic accuracy of such anomalies is reported among the difference centers. Intra- and post-surgical outcomes of women affected by AIP are directly related to the depth and topography of placental invasion, with cases affected by placenta percreta or showing parametrial invasion being at higher risk of morbidity $(1,2)$. Despite this, the actual performance of MRI in detecting the severity of placental invasion remains to be ascertained (8). Furthermore, the strength of association and the predictive accuracy of each MRI sign suggestive of AIP and the severity of placental invasion reain still need to be elucidated. This is fundamental because it would allow a more accuratey stratification of the surgical risk of women suspected to be affected by AIP prenatally.

We have previously reported that MRI had an overall good diagnostic accuracy in detecting all types of AIP (8). The primary aim of this systematic review was to elucidate the overall diagnostic accuracy of prenatal MRI in detecting the severity of placental invasion, defined as the depth and topography of invasion, in women at risk for these anomalies, such as those with ultrasound suspicion or clinical risk factors for AIP. The secondary aim was to explore the strength of association and the predictive accuracy of each MRI sign suggestive of AIP in identifying the severity of placental invasion.

\section{Material and methods}

This review was performed according to an a priori designed protocol and recommended for systematic reviews and meta-analysis (9-11). Medline, Embase, CINAHL and The Cochrane Library including The Cochrane Database of Systematic Reviews (CDSR), Database of Abstracts of Reviews of Effects (DARE) and The Cochrane Central Register of Controlled Trials (CENTRAL) were searched electronically on 23 February 2017, utilizing combinations of the relevant medical subject heading $(\mathrm{MeSH})$ terms, key words, and word variants for "Abnormal invasive placenta" "morbidly adherent placenta" and "MRI" (Supporting Information Table S1). The search and selection criteria were restricted to English. Reference lists of relevant articles and reviews were hand-searched for additional reports. PRISMA and STARD guidelines were followed $(12,13)$. The study was registered with the PROSPERO database (Registration number: CRD42017069636).

The primary aim of the present systematic review was to elucidate the diagnostic accuracy of MRI in recognizing the severity of AIP, defined as the depth and topography of invasion. Inclusion criteria were studies on women who had prenatal MRI for ultrasound suspicion or the presence of clinical risk factors for AIP.

For the depth of placental invasion, the reference standard was histopathological examination of the removed uterus (14). Placenta accreta was diagnosed when anchoring placental villi were attached to myometrium rather than decidua, but without completely invading it. Placenta increta was diagnosed when chorionic villi penetrated the myometrium, and placenta percreta when chorionic villi penetrated the myometrium to the uterine serosa or adjacent organs (14). For the assessment of the topography of placental invasion, we adopted the anatomical classification of AIP proposed by Palacios-Jaraquemada et al. (15).

\section{Key Message}

Magnetic resonance imaging has an excellent diagnostic accuracy in identifying the depth and the topography of placental invasion. 
According to such a classification, the anterior placental invasion was divided into two sectors delimited by a plane perpendicular to the supero-inferior bladder axis, and the uterine sector bordering, the upper posterior bladder wall called S1, and the uterine sector adjacent to the lower posterior wall, S2 (Figure 1). From an anatomical perspective, S1 invasion refers to an invasion situated in the uterine body, whereas S2 to that mainly located in the lower uterine segment or below it. The reference standard was the topography of invasion observed at surgery (15).

The secondary aim was to ascertain the strength of association between each MRI sign suggesting of AIP and the depth of placental invasion and to test their individual predictive accuracy in detecting such invasion.

The MRI signs explored in the present systematic review were:

1. Intra-placental T2 dark bands, defined as nodular or linear areas of low signal intensity on T2-weighted images.

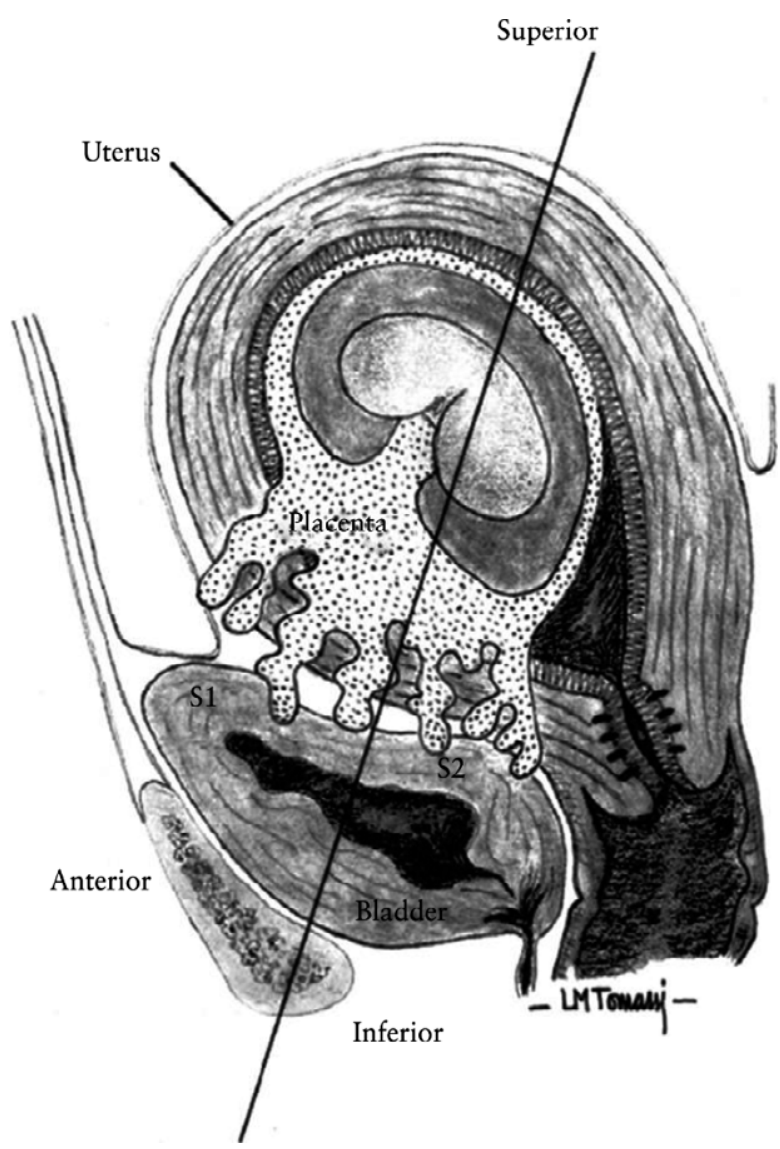

Figure 1. Anatomical representation of topographic classification of abnormally invasive placenta. Anterior placental invasion is divided into two sectors, delimited by a plane perpendicular to supero-inferior bladder axis. Upper posterior bladder wall is labelled as S1 and uterine sector adjacent to lower posterior wall as S2.
2. Uterine bulging, defined as a focal outward contour bulge or disruption of the normal pear shape of the uterus, with the lower uterine segment being wider than the fundus.

3. Heterogeneous placental signal intensity, defined as heterogeneity in the placental parenchyma, which is in normal conditions characterized by a homogeneous intermediate signal intensity.

4. Focal interruption of the myometrium defined as the focal loss of integrity of the myometrial tissue.

5. Tenting of the bladder.

6. Abnormal intra-placental vascularity defined as areas of hyperintense signal on steady-state free precession (SSFP) sequences that are dark on single-shot fast-spin echo (SSFSE), usually having a size of $6 \mathrm{~mm}$ or larger.

7. Focal exophitic mass, defined as placental tissue seen breaking through uterine serosa and extending beyond it, most often seen inside filled urinary bladder. This sign was assessed only for cases affected by placenta percreta.

Studies were assessed according to the following criteria: population, prenatal diagnosis of AIP on MRI, depth of placental invasion and study design. Only studies reporting the diagnostic accuracy of MRI and different MRI signs in detecting the severity of placental invasion based on histopathological diagnosis were considered eligible for the inclusion in the present systematic review. Studies reporting exclusively a clinical diagnosis of AIP, such as difficulty or delay in placental detachment after delivery and those not differentiating among the severity of invasion were excluded. Studies reporting exclusively the prenatal diagnosis of AIP after first or second trimester abortion were also excluded, as were those reporting the prevalence of a given MRI sign only in cases affected by AIP.

Prospective and retrospective cohorts, case-control studies, case reports and case series were analyzed. Opinions and studies carried out only in the second and/or third trimester of pregnancy were excluded. Case reports were also excluded to avoid publication bias. Studies published before 2000 were excluded, as we considered that advances in prenatal imaging techniques and improvements in the diagnosis and definition of AIP make these less relevant.

Two reviewers (F.D.A., A.F.) independently extracted data. Inconsistencies were discussed among the reviewers and consensus reached. Histopathological findings and/or surgical notes were used as a gold standard.

Quality of studies was assessed using the revised tool for the quality assessment of diagnostic accuracy studies 2 (QUADAS-2) (16). This tool evaluates both the risk of bias and the applicability of each study characteristic to 
the research question in four domains (patient selection criteria, choice of index test and of reference standard, and flow of patients); both risk of bias and applicability are scored as "yes", "no" or "unclear", where "yes" stands for low risk of bias and low concern regarding applicability (16).

Funnel plots displaying the outcome rate from individual studies vs. their precision (1/standard error) were carried out with an exploratory aim. Tests for funnel-plot asymmetry were not used when the total number of publications included for each outcome was less than 10. In this case, the power of the test is too low to distinguish chance from real asymmetry.

We evaluated the predictive accuracy of MRI for the detection of four degrees of placental invasion: placenta accreta, increta, accreta or increta, and percreta. The reason for this choice was based upon the fact that placenta percreta is associated with the higher rate of peri-surgical complications compared with placenta accreta and increta. Furthermore, placenta accreta and increta may coexist in the same uterine specimen in women affected by AIP $(8,15)$. Finally, it was not possible, for some of the included studies, to extrapolate data on placenta accreta and increta separately. Thus, in order not to lose potentially relevant information, we decided also to report the different figures of diagnostic accuracy of MRI and different MRI signs in detecting the presence of placenta accreta/increta.

For the detection of placenta accreta, increta, and accreta/increta, we evaluated the association between each of these three outcomes and: (i) an abnormal overall prenatal MRI index; (ii) each of the six prenatal MRI signs included in the overall index: intraplacental dark bands; uterine bulging; heterogeneous signal intensity of the placenta; focal interruption of the myometrium; bladder tenting; abnormal intraplacental vascularity. For the detection of placenta percreta, we used the same approach as described above, but we added a seventh, specific sign to the overall MRI index (direct invasion of the adjacent organs/focal exophitic mass), and we tested the association between the outcome and: (i) the larger composite MRI index; (ii) each of the seven prenatal MRI signs.

We thus performed $(7 * 3)+8=29$ separate meta-analyses, the units of which were single comparisons of subjects with an abnormal (exposed group) vs. normal (unexposed group) MRI sign to predict each of the four outcomes. For each meta-analyses, we first computed summary estimates of sensitivity, specificity, positive and negative likelihood ratios $\left(\mathrm{LR}^{+}\right.$and $\left.\mathrm{LR}^{-}\right)$and diagnostic odds ratio (DOR) using the hierarchical summary receiver-operating characteristics (HSROC) model (17-19). Rutter and Gatsonis HSROC parameterization was used because it models functions of sensitivity and specificity to define a summary ROC curve, and its hierarchical modeling strategy can be used for comparisons of test accuracy when there is variability in threshold between studies (17-19). However, when the number of studies is small, the uncertainty associated with the estimation of the shape parameter may be very high, and models may fail to converge. Thus, for all meta-analyses in which fewer than four study estimates could be pooled, the DerSimonian-Laird random-effect model was used.

Some of the meta-analyses included observational casecontrol studies reporting zero events in one or both the compared groups, and unbalanced exposed and unexposed groups. In these cases, the best performing methods are the Mantel-Haenszel odds ratio without zero-cell continuity corrections, logistic regression and an exact method (20-22). Mantel-Haenszel odds ratios cannot be computed in studies reporting zero events in both groups. However, the exclusion of these may cause a relevant loss of information and the potential inflation of the magnitude of the pooled exposure effect (20-22). Therefore, to keep all studies in the analyses, we also performed all meta-analyses using individual data random-effect logistic regression, with single study as the cluster unit. The pooled datasets with individual data were reconstructed using published $2 \times 2$ tables.

Finally, we performed meta-analyses of proportions to estimate the pooled rates of placenta accreta, increta, accreta+increta and percreta of subjects with and without each MRI sign, respectively. Proportion meta-analyses were performed using a random-effect model to account for inter-study heterogeneity.

The potential publication bias could not formally assessed because of the small numbers of studies and events: formal tests for funnel-plot asymmetry cannot be used when the total number of studies included for each outcome is lower than 10, as their power is too low (20).

STATA command metandi 2013 (Stata Corp., College Station, TX, USA) and META-DISC 1.4 were used to analyze the data $(23,24)$.

\section{Results}

A total of 984 articles were identified. After screening the abstracts, 50 full text articles were assessed with respect to their eligibility for inclusion (Supporting Information Table S2) and 16 studies were included in the systematic review (Table 1, Figure 2) (15,25-39). These 20 studies included 1080 pregnancies at risk for AIP, mainly because of the ultrasound suspicion of such anomalies, thus representing a population already screened for the occurrence of these disorders. Of these, 810 [75\%, 95\% confidence interval (CI) 72.3-77.6] had AIP. Information on the depth of placental invasion was available for 15 studies, whereas one 


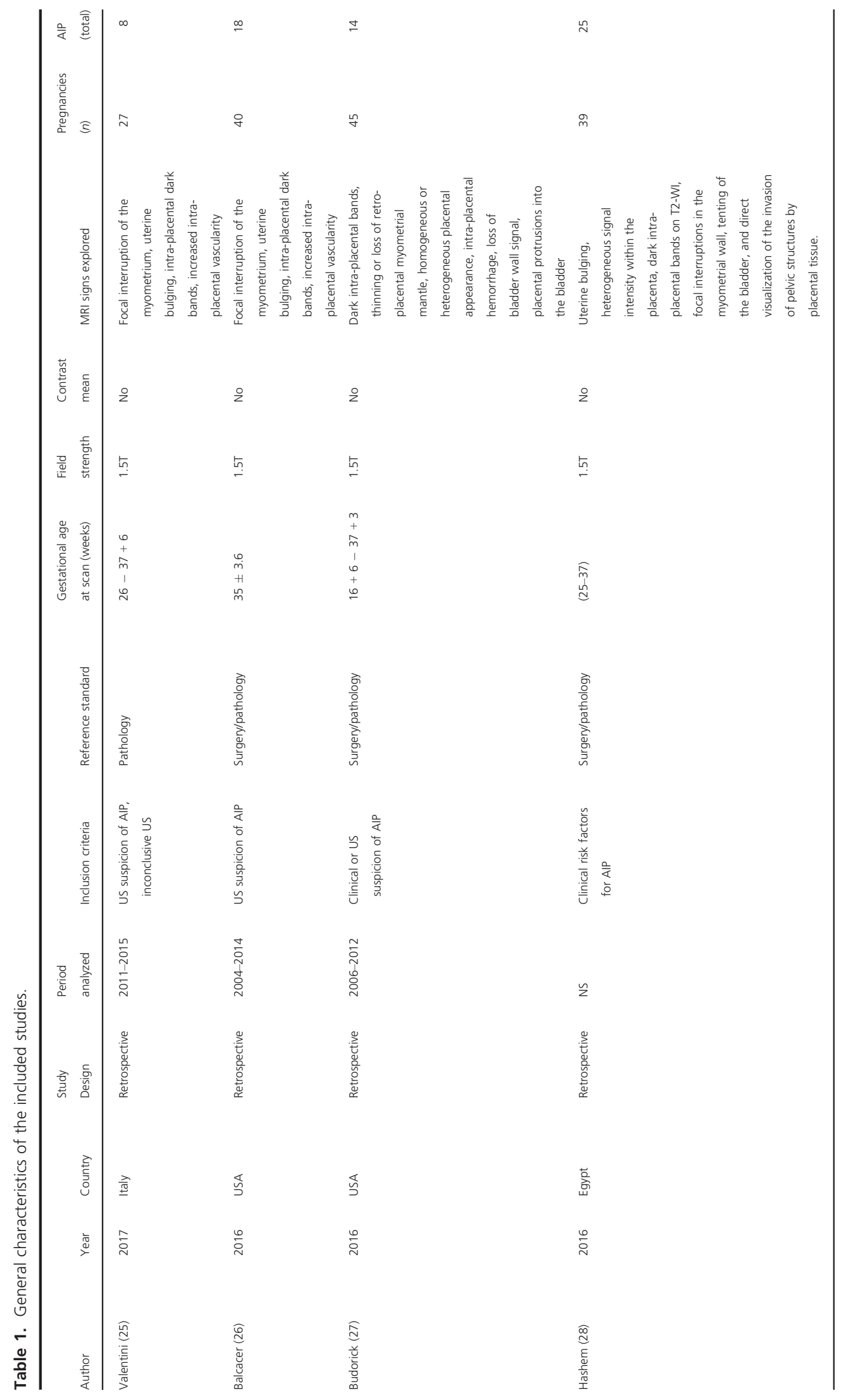




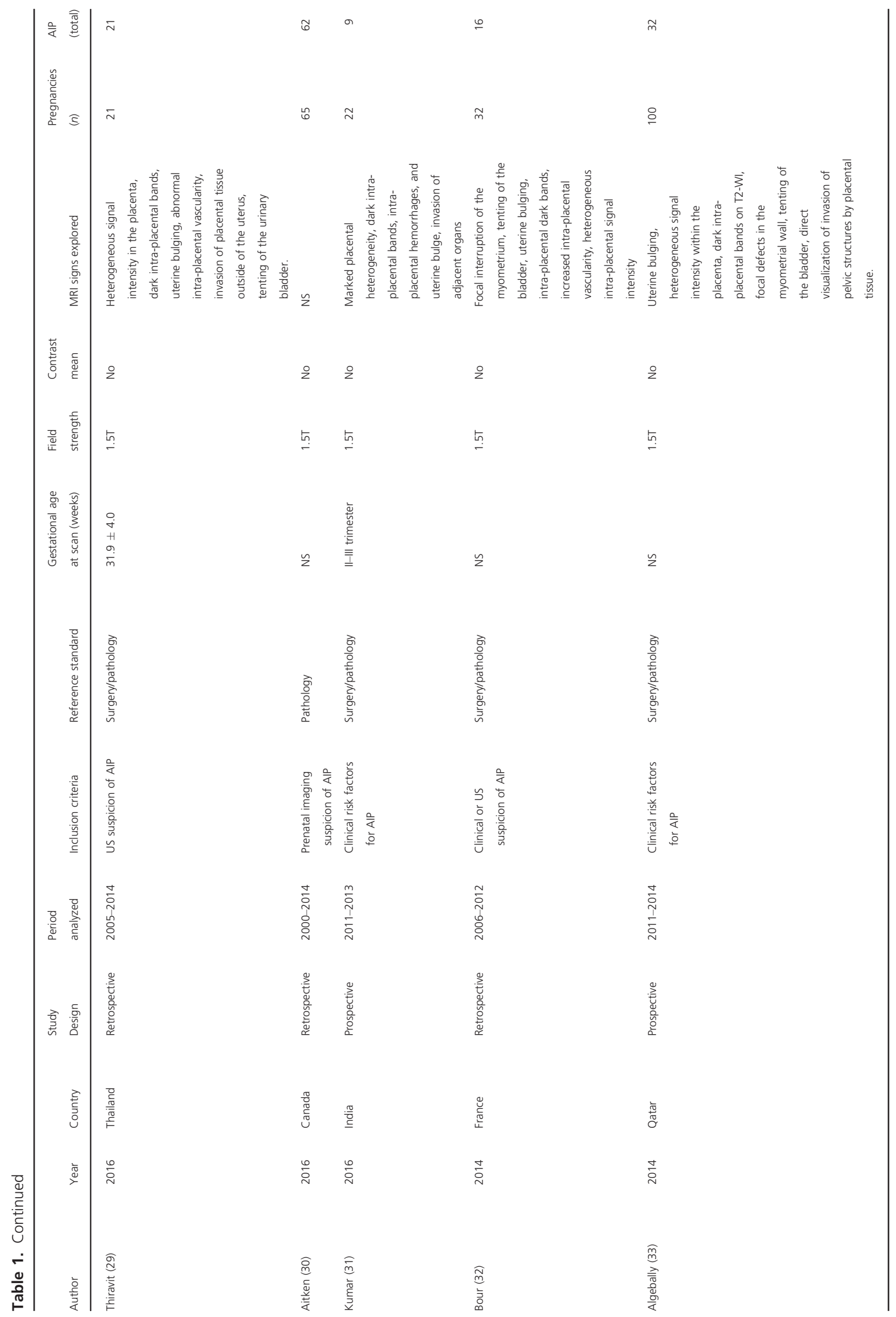




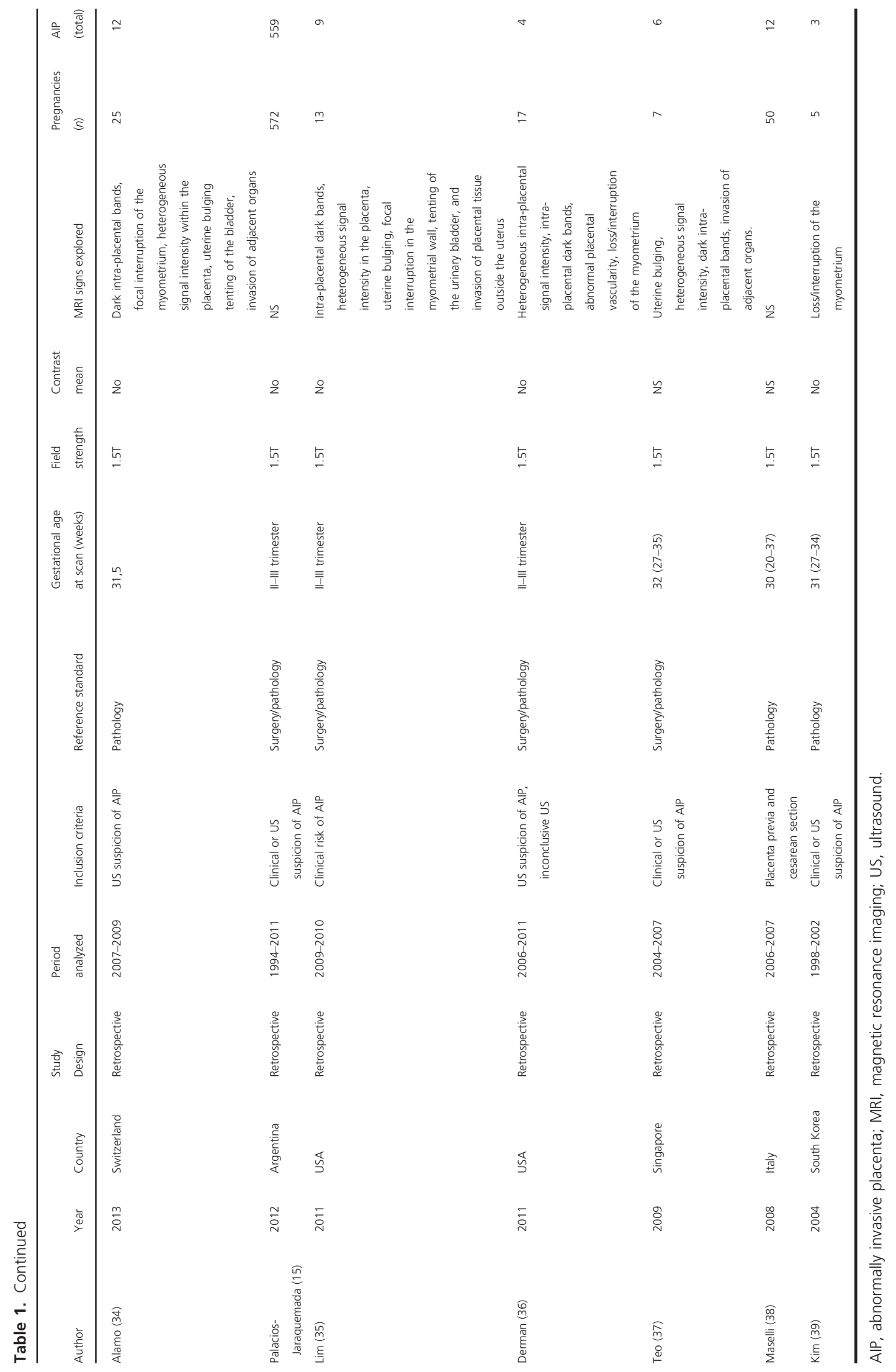




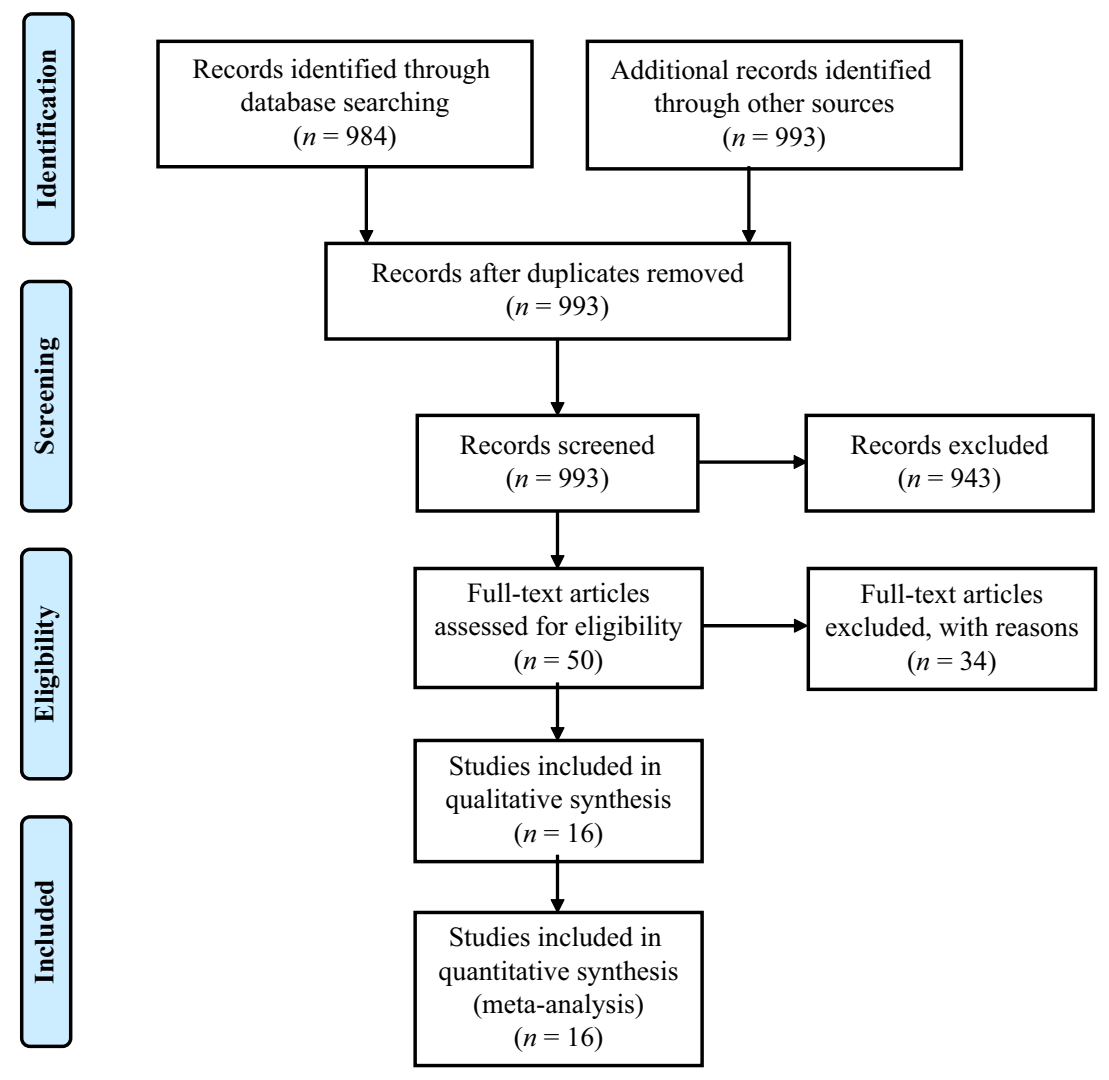

Figure 2. Systematic review flowchart. [Color figure can be viewed at wileyonlinelibrary.com].

reported only the topography of invasion. The occurrence of placenta accreta, increta and percreta was 33.1\% (95\% CI $27.3-439.3), 31.9 \%(95 \%$ CI $26.2-38.0)$ and $35.1 \%$ (95\% CI 29.2-41.3), respectively. SSFSE using a time-toecho of 60-90 ms and SSFP sequences in three planes using an approximate $38 \mathrm{~cm}$ field of view and slice thickness of 5-7 mm were among the most used settings in the included studies. General characteristics of the studies included in the present systematic review are reported in Table 1. Most of the included studies were retrospective series, with different gestational ages at assessment and type of MRI signs explored (Table 1). Quality assessment based on QUADAS-2 guidelines is shown in Figure 3. Most of the studies were of high quality, and there was a low risk of bias and low concern regarding the applicability of the studies.

Nine studies explored the diagnostic performance of MR in detecting the severity of placental invasion based on histopathology $(28,29,31,33-35,37-39)$. MRI had an overall good diagnostic accuracy in identifying the depth of placental invasion, with a sensitivity of $94.4 \%$ (95\% CI $15.8-99.9), 100 \%$ (95\% CI $75.3-100), 95.0 \%$ (95\% CI 86.0-99.0) and $86.5 \%$ (95\% CI 74.2-94.4) for placenta accreta, increta, accreta/increta and percreta, respectively; the corresponding figures for specificity were $98.8 \%(95 \%$ CI 70.7-100), 97.3 (95\% CI 93.3-99.3), 96.0 (95\% CI 92.3-98.3), 96.8 (95\% CI 93.5-98.7). Diagnostic accuracy of MRI in detecting the depth of placental invasion is shown in Table 2.

Only three studies explored the role of MRI in identifying the topography of the invasion $(15,30,38)$. Overall, MRI correctly identified 100\% (95\% CI 97.5-100) of cases with S1 and 100\% (95\% CI 98.5-100) of cases with S2 invasion confirmed at surgery.

Seven studies explored the strength of association between intra-placental dark bands and the severity of placental invasion (25-27,29,35-37). The presence of dark bands was independently associated with placenta accreta, increta and percreta (Supporting Information Table S3) with an OR of 5.2, 15.0 and 7.9, respectively. When translating these findings into figures of diagnostic accuracy, intra-placental dark bands had a sensitivity of $89.7 \%$ (95\% CI $44.2-99.0), 89.7 \%$ (95\% CI $72.6-97.8)$ and $82.6 \%$ (95\% CI 68.6-91.1) for the detection of placenta accreta, increta and percreta, respectively; the corresponding figures for specificity were $49.5 \%$ (95\% CI 26.9-72.3), 63.4\% (95\% CI $54.7-71.6)$ and $58.5 \%$ (95\% CI $38.3-$ 76.2). DOR of intra-placental dark bands in the detection 


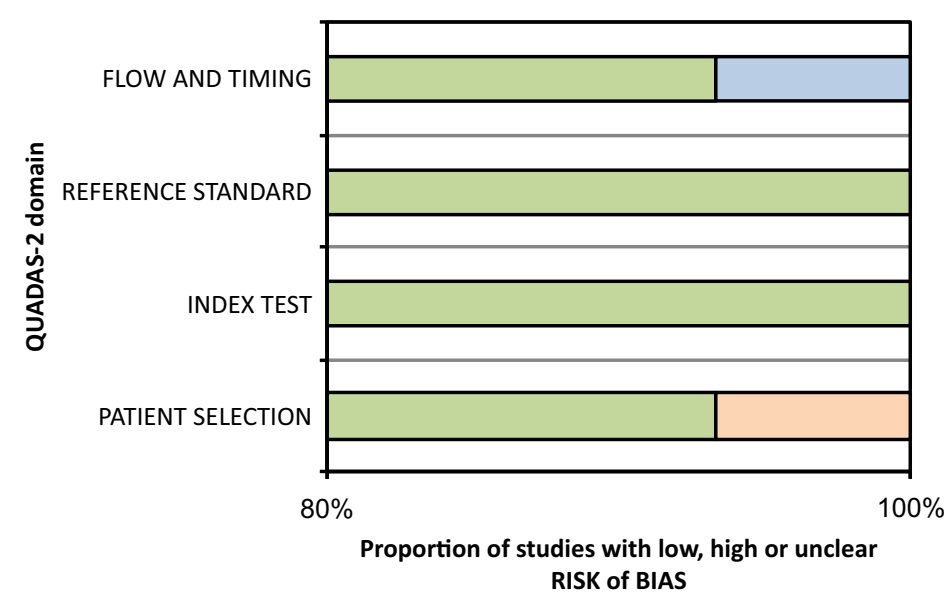

\section{¿Low $\square$ High $\square$ Unclear}

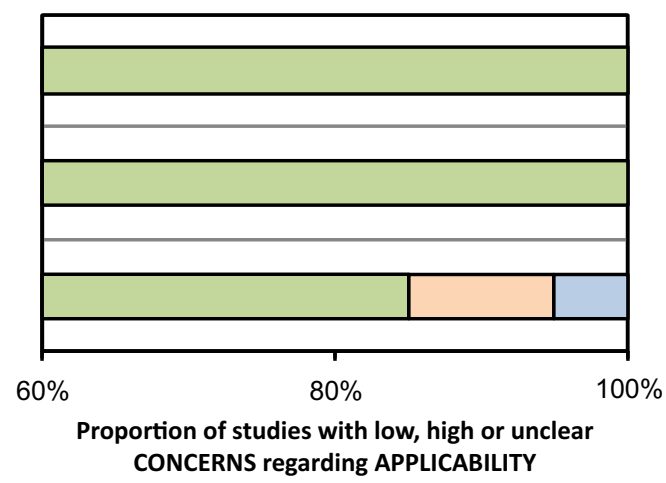

Figure 3. QUADAS-2 assessment of the studies included in the systematic review. [Color figure can be viewed at wileyonlinelibrary.com].

of the depth of placental invasion was 8.5, 9.3 and 6.7 for placenta accreta, increta and percreta.

Eight studies explored the strength of association and the predictive accuracy of the presence of uterine bulging in recognizing the depth of placental invasion (25$29,32,35,37)$. Uterine bulging was associated with a higher risk of increta and percreta, with an OR of 6.1 and 6.3, respectively, but not of placenta accreta. Sensitivity and specificity of uterine bulging in identifying placenta accreta were $54.5 \%$ (95\% CI $32.2-75.6$ ) and 58.8\% (95\% CI 49.8-67.3), while the corresponding figures for placenta increta and percreta were $76.7 \%$ (95\% CI 52.8-90.6) and 62.5\% (95\% CI $40.9-80.0)$ and $77.4 \%$ (95\% CI $62.6-$ 87.5 ) and $64.7 \%$ (95\% CI 50.3-76.9) (Tables 3-6; Supporting Information Tables S3 and S4).

Six studies explored the association between heterogeneous signal intensity in the placenta and different types of AIP $(25,27,28,32,36,37)$. The presence of a heterogeneous signal intensity was associated with a higher risk of every type of AIP, with an OR of 5.8, 16.5, 7.9 and 3.5 for placenta accreta, increta, accreta/increta and percreta, respectively. Sensitivity and specificity were 75.0 (42.894.5) and $65.9 \%$ (95\% CI 54.6-76.0) for placenta accreta, $81.8 \%$ (95\% CI $48.2-97.7)$ and $71.1 \%$ (95\% CI $59.5-$ 80.9) for placenta increta, $80.9 \%$ (95\% CI 41.5-96.2) and 67.4\% (95\% CI 41.2-85.9) for placenta accreta/increta, and $73.9 \%$ (95\% CI $39.7-92.4)$ and $62.7 \%$ (95\% CI $43.8-$ 78.4) for placenta percreta (Tables 3-6).

Seven studies explored the strength of association and predictive accuracy of focal interruption of the myometrium in identifying the severity of AIP (Tables S3 and S4) $(25-28,32,35,39)$. Interruption of the myometrium was significantly associated with placenta accreta, increta and percreta, with an OR of 4.4, 7.5 and 8.7, respectively. Interruption of the myometrium had a sensitivity, a specificity and a DOR of $63.6 \%$ (95\% CI 40.7-82.8),
$72.2 \%(95 \%$ CI $62.8-80.4)$ and 3.5 (95\% CI $0.9-14.5)$ in identifying cases with placenta accreta. Sensitivity and specificity for placenta increta and percreta were $71.5 \%$ (95\% CI $48.5-87.0)$ and $74.6 \%$ (95\% CI 63.0-83.4) and $78.6 \%$ (95\% CI $59.0-91.7)$ and $70.2 \%$ (95\% CI $62.7-$ 77.0), respectively.

The presence of focal exophitic mass extending into the bladder was analyzed only for cases with placenta percreta and was explored only by five studies $(25,28,29,31,37)$. Detection of exophitic mass at fetal MRI was independently associated with placenta percreta with an OR of 278 (Table S3). When translating this finding into figures of diagnostic accuracy, sensitivity, specificity, $\mathrm{LR}^{+}, \mathrm{LR}^{-}$and DOR were $69.2 \%, 98.9 \%, 64.3,0.3$ and 206, respectively (Table 6).

The presence of bladder tenting was significantly associated only with the placenta percreta, with an OR of 12.8 (95\% CI 2.7-61.4) and showed a sensitivity of 52.6\% (95\% CI 28.9-75.6), a specificity of $90.2 \%$ (95\% CI $79.8-$ 96.3), a DOR of 9.0 (95\% CI 1.8-43.8), an $\mathrm{LR}^{+}$of 4.2 (95\% CI 1.6-11.2) and an $\mathrm{LR}^{-}$of 0.6 (95\% CI 04-0.9).

Finally, abnormal intra-placental vascularity was significantly associated with placenta accreta (OR 4.4, 95\% CI 1.6-12.3), increta (OR 3.2, 95\% CI 1.3-8.1) and percreta (OR 4.0, 95\% CI 1.5-10.5). Sensitivity of abnormal intraplacental vascularity was $53.8 \%(95 \%$ CI $28.3-77.4)$ for placenta accreta, $46.0 \%(95 \%$ CI $27.8-65.2)$ for placenta increta, and $46.4 \%$ (95\% CI 26.4-67.7) for placenta percreta. The corresponding figures for specificity were $80.9 \%$ (95\% CI $68.9-89.0), 80.0 \%$ (95\% CI 66.4-89.1) and $79.8 \%(95 \%$ CI $68.7-87.7)$.

\section{Discussion}

The findings from this systematic review showed that prenatal MRI has an excellent diagnostic accuracy in 
identifying the depth and the topography of placental invasion. However, these findings come from studies in which MRI was performed as a secondary imaging tool in women already screened for AIP on ultrasound and might not reflect its actual diagnostic performance in detecting the severity of these disorders. Small number of included studies, their retrospective design, heterogeneity in MRI signs explored and gestational ages at assessment represent the main limitations of the present systematic review.

Ultrasound is usually the primary tool in assessing women at risk for AIP, such those presenting with placenta previa and a prior cesarean section, whereas MRI is performed only to confirm the diagnosis or in case of inconclusive ultrasound assessment. The large majority of women included in the present systematic review were referred to MRI in view of the ultrasound suspicion of AIP, thus representing a population already screened for these disorders. In this scenario, the figures reported here may not represent the actual diagnostic performance of MRI in detecting the severity of AIP. Lack of stratification of the analysis according to gestational age at scan and maternal characteristics represents another major limitation of the present systematic review. Interpretation of individual signs is another relevant issue; the diagnostic accuracy of MRI has been shown to be significantly affected by operator experience (34). Furthermore, there is no complete agreement yet on how to label the different imaging signs suggestive of AIP, and it might be entirely possible for the same imaging sign to be named differently by different operators. Finally, surgical assessment of the severity and topography of placental invasion was not blinded to the imaging reports in the large majority of included cases. Despite these limitations, the present systematic review represents the most comprehensive assessment of the diagnostic accuracy of MRI in detecting the severity of invasion.

Accurate prenatal diagnosis of the severity of AIP is fundamental to tailor the optimal surgical approach. The two major determinants of surgical outcome in women affected by AIP are the depth and extension of placental invasion (40). Depth of placental invasion refers to the degree of invasion through the myometrium. Invasion of the bladder and adjacent organs is significantly associated with a higher risk of massive hemorrhage and surgical complications than is a lesser degree of invasion, such as that occurring in placenta accreta. It is therefore fundamental to identify those cases at higher risk of placenta percreta to plan an appropriate surgical management $(1,2)$. We have previously reported that ultrasound has an overall good diagnostic accuracy in identifying the depth of placental invasion with a sensitivity of $90.6 \%(95 \% \mathrm{CI}$ 80.7-96.5), 93.0\% (95\% CI 80.9-98.5), and 81.2\% (95\% 
Table 3. Summary estimates of sensitivity, specificity, positive and negative likelihood ratios ( $L R^{+}$and $L R^{-}$) and diagnostic odds ratio (DOR) of each MRI sign to predict a diagnosis of placenta accreta. Computations were based upon DerSimonian-Laird random-effect $\left({ }^{\Psi}\right)$ or hierarchical summary receiver operating characteristic (HSROC) model $\left({ }^{\Omega}\right)$.

\begin{tabular}{|c|c|c|c|c|c|c|c|}
\hline MRI sign & $\begin{array}{l}\mathrm{N} . \\
\text { studies }\end{array}$ & References & $\begin{array}{l}\text { Sensitivity \% } \\
(95 \% \text { CI) }\end{array}$ & $\begin{array}{l}\text { Specificity \% } \\
(95 \% \text { CI) }\end{array}$ & $\begin{array}{l}\text { DOR } \\
(95 \% \mathrm{Cl})\end{array}$ & $\mathrm{LR}^{+}(95 \% \mathrm{Cl})$ & $\mathrm{LR}^{-}(95 \% \mathrm{Cl})$ \\
\hline $\begin{array}{l}\text { 1. Intraplacental dark } \\
\text { bands }\end{array}$ & $7^{\Omega}$ & $25-27,29,35-37$ & $89.7(44.2-99.0)$ & $49.5(26.9-72.3)$ & $8.50(0.99-72.7)$ & $1.77(1.15-2.74)$ & $0.21(0.03-1.51)$ \\
\hline 2. Uterine bulging & $6^{\Omega}$ & $25,25-27,27,29$ & $54.5(32.2-75.6)$ & $58.8(49.8-67.3)$ & $1.54(0.59-4.0)$ & $1.24(0.77-1.99)$ & $0.89(0.56-1.42)$ \\
\hline $\begin{array}{l}\text { 3. Heterogeneous } \\
\text { placental signal } \\
\text { intensity }\end{array}$ & $4^{\Omega}$ & $25,27,36,37$ & $75.0(42.8-94.5)$ & $65.9(54.6-76.0)$ & $4.25(1.08-16.8)$ & $1.75(0.94-3.27)$ & $0.51(0.21-1.24)$ \\
\hline $\begin{array}{l}\text { 4. Focal myometrial } \\
\text { interruption }\end{array}$ & $5^{\Omega}$ & $25,25-27,29$ & $63.6(40.7-82.8)$ & $72.2(62.8-80.4)$ & $3.53(0.85-14.5)$ & $2.33(1.38-3.95)$ & $0.59(0.23-1.51)$ \\
\hline 5. Bladder tenting & $2^{\Psi}$ & 25,29 & $42.9(9.90-81.6)$ & $75.6(59.7-87.6)$ & $3.07(0.54-17.5)$ & $1.99(0.69-5.78)$ & $0.71(0.37-1.37)$ \\
\hline $\begin{array}{l}\text { 6. Abnormal } \\
\text { intraplacental } \\
\text { vascularity }\end{array}$ & $5^{\Omega}$ & $25-27,29,36$ & $53.8(28.3-77.4)$ & $80.9(68.9-89.0)$ & $4.92(1.68-14.4)$ & $2.81(1.54-5.13)$ & $0.57(0.33-1.0)$ \\
\hline
\end{tabular}

$\mathrm{Cl}$, confidence interval.

Table 4. Summary estimates of sensitivity, specificity, positive and negative likelihood ratios $\left(\mathrm{LR}^{+}\right.$and $\mathrm{LR}^{-}$) and diagnostic odds ratio (DOR) of each MRI sign to predict a diagnosis of placenta increta. Computations were based upon DerSimonian-Laird random-effect $\left({ }^{\Psi}\right)$ or hierarchical summary receiver operating characteristic (HSROC) model $\left({ }^{\Omega}\right)$.

\begin{tabular}{|c|c|c|c|c|c|c|c|}
\hline MRI sign & $\begin{array}{l}\text { No. of } \\
\text { studies }\end{array}$ & References & $\begin{array}{l}\text { Sensitivity \% } \\
(95 \% \text { CI) }\end{array}$ & $\begin{array}{l}\text { Specificity \% } \\
(95 \% \text { CI) }\end{array}$ & DOR $(95 \% \mathrm{Cl})$ & $\mathrm{LR}^{+}(95 \% \mathrm{Cl})$ & $\mathrm{LR}^{-}(95 \% \mathrm{CI})$ \\
\hline $\begin{array}{l}\text { 1. Intraplacental } \\
\text { dark bands }\end{array}$ & $6^{\Omega}$ & $25-27,29,35,36$ & $89.7(72.6-97.8)$ & $63.4(54.7-71.6)$ & $9.27(3.19-26.9)$ & $2.01(1.25-3.24)$ & $0.29(0.13-0.65)$ \\
\hline 2. Uterine bulging & $5^{\Omega}$ & $25-27,29,35$ & $76.7(52.8-90.6)$ & $62.5(40.9-80.0)$ & $5.48(1.91-15.7)$ & $2.04(1.25-3.35)$ & $0.37(0.18-0.79)$ \\
\hline $\begin{array}{l}\text { 3. Heterogeneous } \\
\text { placental signal } \\
\text { intensity }\end{array}$ & $3^{\Psi}$ & $25,27,36$ & $81.8(48.2-97.7)$ & $71.1(59.5-80.9)$ & $11.4(2.72-48.1)$ & $2.92(1.06-8.01)$ & $0.31(0.12-0.85)$ \\
\hline $\begin{array}{l}\text { 4. Focal } \\
\text { myometrial } \\
\text { interruption }\end{array}$ & $4^{\Omega}$ & $25-27,35$ & $71.5(48.5-87.0)$ & $74.6(63.0-83.4)$ & $7.35(2.40-22.5)$ & $2.81(1.72-4.59)$ & $0.38(0.19-0.78)$ \\
\hline 5. Bladder tenting & $2^{\Psi}$ & 25,29 & $33.3(7.50-70.1)$ & $77.3(62.2-88.5)$ & $2.63(0.03-267)$ & $1.67(0.06-46.6)$ & $0.61(0.04-10.6)$ \\
\hline $\begin{array}{l}\text { 6. Abnormal } \\
\text { intraplacental } \\
\text { vascularity }\end{array}$ & $5^{\Omega}$ & $25-27,29,36$ & $46.0(27.8-65.2)$ & $80.0(66.4-89.1)$ & $3.41(1.27-9.12)$ & $2.30(1.19-4.45)$ & $0.68(0.47-0.98)$ \\
\hline
\end{tabular}

$\mathrm{Cl}$, confidence interval.

CI 51.8-94.6) and a specificity of $97.1 \%$ (95\% CI $95.4-$ 98.3), 98.4 (95\% CI 97.0-99.2), 98.9 (95\% CI 95.0-100) for placenta accreta, increta, accreta/increta and percreta, respectively. The findings from this systematic review showed that the diagnostic accuracy of MRI in detecting the depth of placental invasion is similar to ultrasound.

The relatively lower sensitivity of MRI in detecting placenta percreta compared with less severe types of AIP might initially look surprising, especially when considering that ultrasound has been reported to have a similar diagnostic performance in detecting this type of invasion (41). Placenta percreta is classically defined as chorionic villi penetrating through the myometrium to the uterine serosa, but it is not a unique condition; it can be confined to the uterine serosa or associated with a massive infiltration of the parametria, bladder and adjacent organs. In this scenario, the prevalence of MRI signs can be different according to the type of extra-uterine invasion. Gestational age at MRI represents another relevant issue. Although no randomized trial on the optimal timing at MRI has been published, it is the collective authors' experience that a later gestational age at scan (>30 weeks) may affect the detection of AIP. Increase in uterus size and subsequent stretching of the myometrium with advancing gestation will make it difficult to detect focal myometrial thinning adjacent to a bulging placenta 
Table 5. Summary estimates of sensitivity, specificity, positive and negative likelihood ratios $\left(\mathrm{LR}^{+}\right.$and $\mathrm{LR}^{-}$) and diagnostic odds ratio (DOR) of each MRI sign to predict a diagnosis of placenta accreta+increta. Computations were based upon DerSimonian-Laird random-effect $\left({ }^{\Psi}\right)$ or hierarchical summary receiver operating characteristic (HSROC) model $\left(^{\Omega}\right)$.

\begin{tabular}{|c|c|c|c|c|c|c|c|}
\hline MRI signs & $\begin{array}{l}\text { No. of } \\
\text { studies }\end{array}$ & References & $\begin{array}{l}\text { Sensitivity \% } \\
(95 \% \mathrm{Cl})\end{array}$ & $\begin{array}{l}\text { Specificity \% } \\
(95 \% \text { Cl) }\end{array}$ & DOR $(95 \% \mathrm{Cl})$ & $\mathrm{LR}^{+}(95 \% \mathrm{Cl})$ & $\mathrm{LR}^{-}(95 \% \mathrm{Cl})$ \\
\hline $\begin{array}{l}\text { 1. Intraplacental } \\
\text { dark bands }\end{array}$ & $9^{\Omega}$ & $25-29,32,35-37$ & $87.6(59.1-97.2)$ & $64.7(44.5-80.8)$ & $13.0(2.98-56.4)$ & $2.48(1.52-4.06)$ & $0.19(0.05-0.70)$ \\
\hline 2. Uterine bulging & $8^{\Omega}$ & $25-29,32,35,37$ & $63.8(49.1-76.3)$ & $63.0(41.8-80.2)$ & $3.0(1.34-6.76)$ & $1.73(1.06-2.82)$ & $0.57(0.39-0.84)$ \\
\hline $\begin{array}{l}\text { 3. Heterogeneous } \\
\text { placental signal } \\
\text { intensity }\end{array}$ & $6^{\Omega}$ & $25,27,28,32,36,37$ & $80.9(41.5-96.2)$ & $67.4(41.2-85.9)$ & $8.76(1.05-72.8)$ & $2.48(1.10-5.61)$ & $0.28(0.06-1.27)$ \\
\hline $\begin{array}{l}\text { 4. Focal } \\
\text { myometrial } \\
\text { interruption }\end{array}$ & $7^{\Omega}$ & $25-28,32,35,39$ & $67.9(54.7-78.7)$ & $77.5(67.2-85.3)$ & $7.28(3.19-16.7)$ & $3.02(1.89-4.82)$ & $0.41(0.27-0.63)$ \\
\hline 5. Bladder tenting & $3^{\Psi}$ & $25,29,32$ & $23.1(9.0-43.6)$ & $81.5(68.6-90.7)$ & $1.25(0.06-24.4)$ & $1.20(0.12-11.7)$ & $0.99(0.54-1.82)$ \\
\hline $\begin{array}{l}\text { 6. Abnormal } \\
\text { intraplacental } \\
\text { vascularity }\end{array}$ & $6^{\Omega}$ & $25-27,29,32,36$ & $42.3(22.2-65.2)$ & $83.2(69.4-91.5)$ & $3.62(0.95-13.7)$ & $2.51(1.0-6.31)$ & $0.69(0.45-1.08)$ \\
\hline
\end{tabular}

$\mathrm{Cl}$, confidence interval.

Table 6. Summary estimates of sensitivity, specificity, positive and negative likelihood ratios $\left(\mathrm{LR}^{+}\right.$and $\mathrm{LR}^{-}$) and diagnostic odds ratio (DOR) of each MRI sign to predict a diagnosis of placenta percreta. Computations were based upon DerSimonian-Laird random-effect $\left({ }^{\Psi}\right)$ or hierarchical summary receiver operating characteristic (HSROC) model $\left({ }^{\Omega}\right)$.

\begin{tabular}{|c|c|c|c|c|c|c|c|}
\hline MRI sign & $\begin{array}{l}\text { No. of } \\
\text { studies }\end{array}$ & References & $\begin{array}{l}\text { Sensitivity \% } \\
(95 \% \text { CI) }\end{array}$ & $\begin{array}{l}\text { Specificity \% } \\
(95 \% \text { CI) }\end{array}$ & DOR $(95 \% \mathrm{Cl})$ & $\mathrm{LR}^{+}(95 \% \mathrm{CI})$ & $\mathrm{LR}^{-}(95 \% \mathrm{CI})$ \\
\hline $\begin{array}{l}\text { 1. Intraplacental } \\
\text { dark bands }\end{array}$ & $9^{\Omega}$ & $25-29,32,35-37$ & $82.6(68.6-91.1)$ & $58.5(38.3-76.2)$ & $6.66(2.31-19.2)$ & $1.98(1.23-3.22)$ & $0.30(0.15-0.59)$ \\
\hline 2. Uterine bulging & $8^{\Omega}$ & $25-29,32,35,37$ & $77.4(62.6-87.5)$ & $64.7(50.3-76.9)$ & $6.28(2.60-15.2)$ & $2.19(1.47-3.28)$ & $0.35(0.20-0.62)$ \\
\hline $\begin{array}{l}\text { 3. Heterogeneous } \\
\text { placental signal } \\
\text { intensity }\end{array}$ & $6^{\Omega}$ & $25,27,28,32,36,37$ & $73.9(39.7-92.4)$ & $62.7(43.8-78.4)$ & $4.76(0.99-22.8)$ & $1.98(1.11-3.54)$ & $0.42(0.14-1.23)$ \\
\hline $\begin{array}{l}\text { 4. Focal } \\
\text { myometrial } \\
\text { interruption }\end{array}$ & $6^{\Omega}$ & $25-28,32,35$ & $78.6(59.0-91.7)$ & $70.2(62.7-77.0)$ & $6.46(2.47-16.9)$ & $2.42(1.71-3.42)$ & $0.42(0.22-0.78)$ \\
\hline 5. Bladder tenting & $3^{\Psi}$ & $25,29,32$ & $52.6(28.9-75.6)$ & $90.2(79.8-96.3)$ & $8.95(1.83-43.8)$ & $4.17(1.56-11.2)$ & $0.56(0.35-0.92)$ \\
\hline $\begin{array}{l}\text { 6. Abnormal } \\
\text { intraplacental } \\
\text { vascularity }\end{array}$ & $6^{\Omega}$ & $25-27,29,32,36$ & $46.4(26.4-67.7)$ & $79.8(68.7-87.7)$ & $3.43(1.25-9.44)$ & $2.30(1.22-4.34)$ & $0.67(0.44-1.02)$ \\
\hline $\begin{array}{l}\text { 7. Direct invasion/ } \\
\text { focal exophitic } \\
\text { mass }\end{array}$ & $5^{\Omega}$ & $25,28,29,31,37$ & $69.2(41.8-87.5)$ & $98.9(57.8-100)$ & $206(2.89-14,751)$ & $64.3(1.01-4080)$ & $0.31(0.14-0.68)$ \\
\hline
\end{tabular}

adjacent to the serosa. Furthermore, heterogeneous signal intensity and infarcts are more commonly seen later on in pregnancy due to physiologic placenta aging, thus confounding the assessment of the presence and type of placental invasion. Finally, studies on ultrasound diagnosis of AIP include longitudinal assessment of women at risk for these conditions, such as those with placenta previa and prior cesarean section, whereas MRI is usually performed only once during gestation. In this scenario, it is clinically plausible that serial assessments through pregnancy may improve the diagnostic accuracy of ultrasound in detecting AIP, also considering that signs of advanced placenta invasion may become apparent only later on in gestation, thus partially explaining the similar diagnostic performance of ultrasound and MRI in detecting placenta percreta.

The topography of placental invasion is the other major determinant in predicting surgical outcome in women with AIP (15). Irrespective of the depth of invasion, AIP occurring in the inferior third of the lower uterine segment is likely to be associated with increased surgical difficulties compared with that affecting the 
upper part of the uterine segment. Palacios-Jaraquemada et al. provide an objective anatomical classification of AIP invasion which is mainly applicable to women with anterior placental invasion (15). According to this classification, anterior placental invasion is divided into two sectors, delimited by a plane perpendicular to superoinferior bladder axis. The upper posterior bladder wall is labelled as S1 and uterine sector adjacent to lower posterior wall as S2. The importance of such a classification is that it can predict surgical outcome, with women showing S2 invasion being at higher risk of complications during surgery. Despite this, such classification still requires validation in large prospective studies. In the present review, MRI was able to identify accurately all cases of S1 and S2 invasion. Conversely, we have previously reported that the detection rate of ultrasound in detecting S1 and S2 invasion was 93.4\% (95\% CI 64.7$100)$ and $90.3 \% \quad(95 \%$ CI 80.7-97.4), respectively. Although it might seem that MRI has an overall better accuracy in correctly describing the topography of placenta invasion compared with ultrasound, these results should be interpreted with caution. The small number of included cases and lack of data on specificity highlight the need for large studies aiming at validating such a diagnostic approach and at comparing the performance of MRI and ultrasound in correctly identifying the topography of placental invasion. However, until further evidence is available, it may be reasonable to perform an MRI in women suspected to be affected by severe types of AIP in order to delineate the topography of placental invasion, especially when a resective procedure such as hysterectomy is planned.

Further large prospective studies integrating pregnancy characteristics, ultrasound and MRI signs are needed to standardize prenatal diagnosis of AIP and to provide predictive models able to anticipate surgical outcome of women affected by AIP.

\section{Funding}

No specific funding was obtained for this study.

\section{References}

1. Belfort MA. Placenta accreta. Am J Obstet Gynecol. 2010;203:430-9.

2. Oyelese Y, Smulian JC. Placenta previa, placenta accreta, and vasa previa. Obstet Gynecol. 2006;107:927-41.

3. Miller DA, Chollet JA, Goodwin TM. Clinical risk factors for placenta previa-placenta accreta. Am J Obstet Gynecol. 1997;177:210-4.

4. Jauniaux E, Collins S, Burton GJ. Placenta accreta spectrum: pathophysiology and evidence-based anatomy for prenatal ultrasound imaging. Am J Obstet Gynecol. 2017; Jun 24. pii: S0002-9378(17)30731-7. https://doi.org/ 10.1016/j.ajog.2017.05.067.

5. Timor-Tritsch IE, Monteagudo A. Unforeseen consequences of the increasing rate of cesarean deliveries: early placenta accreta and cesarean scar pregnancy. A review. Am J Obstet Gynecol. 2012;207:14-29.

6. Tikkanen M, Paavonen MRIJ, Loukovaara M, Stefanovic V. Antenatal diagnosis of placenta accreta leads to reduced blood loss. Acta Obstet Gynecol Scand. 2011;90:1140-6.

7. Silver RM, Fox KA, Barton JR, Abuhamad AZ, Simhan H, Huls CK, et al. Center of excellence for placenta accreta. Am J Obstet Gynecol. 2015;212:561-8.

8. D’Antonio F, Iacovella C, Palacios-Jaraquemada J, Bruno $\mathrm{CH}$, Manzoli L, Bhide A. Prenatal identification of invasive placentation using magnetic resonance imaging: systematic review and meta-analysis. Ultrasound Obstet Gynecol. 2014;44:8-16.

9. Henderson LK, Craig JC, Willis NS, Tovey D, Webster AC. How to write a Cochrane systematic review. Nephrology. 2010;15:617-24.

10. NHS Centre for Reviews and Dissemination. Systematic reviews: CRD's guidance for undertaking reviews in health care. York: University of York, 2009.

11. Leeflang MM, Deeks JJ, Gatsonis C, Bossuyt PM; Cochrane Diagnostic Test Accuracy Working Group. Systematic reviews of diagnostic test accuracy. Ann Intern Med. 2008;149:889-97.

12. Prisma statement. http://www.prisma-statement.org/ (accessed 10 March 2017).

13. Bossuyt PM, Reitsma JB, Bruns DE, Gatsonis CA, Glasziou PP, Irwig LM, et al. ; Standards for Reporting of Diagnostic Accuracy. Towards complete and accurate reporting of studies of diagnostic accuracy: the STARD initiative. Ann Intern Med. 2003;138:40-4.

14. Benirschke K, Kaufmann P, Baergen RN. Pathology of the human placenta, 5th edn. New York: Springer-Verlag, 2006.

15. Palacios-Jaraquemada JM, Bruno CH, Martín E. MRI in the diagnosis and surgical management of abnormal placentation. Acta Obstet Gynecol Scand. 2013;92:392-7.

16. Whiting PF, Rutjes AW, Westwood ME, Mallett S, Deeks JJ, Reitsma JB, et al. ; QUADAS-2 Group. QUADAS-2: a revised tool for the quality assessment of diagnostic accuracy studies. Ann Intern Med. 2011;155:529-36.

17. Rutter CM, Gatsonis CA. A hierarchical regression approach to meta-analysis of diagnostic test accuracy evaluations. Stat Med. 2001;20:2865-84.

18. Glas AS, Lijmer JG, Prins MH, Bonsel GJ, Bossuyt PM. The diagnostic odds ratio: a single indicator of test performance. J Clin Epidemiol. 2003;56:1129-35.

19. Cochrane Handobook for Systematic Reviews of Diagnostic Test Accuracy, Chapter 10; http://srdta.cochra ne.org/handbook-dta-reviews

20. Hunter JP, Saratzis A, Sutton AJ, Boucher RH, Sayers RD, Bown MJ. In meta-analyses of proportion studies, funnel 
plots were found to be an inaccurate method of assessing publication bias. J Clin Epidemiol. 2014;67:897-903.

21. Higgins JPT, Green S (editors). Cochrane Handbook for Systematic Reviews of Interventions Version 5.0.2 [updated September 2009]. The Cochrane Collaboration, 2009. http://www.cochrane-handbook.org (accessed 1 March 2017).

22. Egger M, Davey Smith G, Schneider M, Minder C. Bias in meta-analysis detected by a simple, graphical test. BMJ. 1997;315:629-34.

23. Harbord RM, Whiting P. Metandi: meta-analysis of diagnostic accuracy using hierarchical logistic regression. Stata J. 2009;9:211-29.

24. Zamora J, Abraira V, Muriel A, Khan K, Coomarasamy A. Meta-DiSc: a software for meta-analysis of test accuracy data. BMC Med Res Methodol. 2006;6:31.

25. Valentini AL, Gui B, Ninivaggi V, Miccò M, Giuliani M, Russo L, et al. The morbidly adherent placenta: when and what association of signs can improve MRI diagnosis? Our experience Diagn Interv Radiol. 2017;23:180-6.

26. Balcacer P, Pahade J, Spektor M, Staib L, Copel JA, McCarthy S. Magnetic resonance imaging and sonography in the diagnosis of placental invasion. J Ultrasound Med. 2016;35:1445-6.

27. Budorick NE, Figueroa R, Vizcarra M, Shin J. Another look at ultrasound and magnetic resonance imaging for diagnosis of placenta accreta. J Matern Fetal Neonatal Med. 2016;24:1-6.

28. Hashem LB, Salem DS, Hamed ST, Hussein AM. Role of MRI versus ultrasound in the assessment of placental abnormalities and diseases. Egypt J Radiol Nucl Med. 2016;47:641-58.

29. Thiravit S, Lapatikarn S, Muangsomboon K, Suvannarerg V, Thiravit P, Korpraphong P. MRI of placenta percreta: differentiation from other entities of placental adhesive disorder. Radiol Med. 2017;122:61-8.

30. Aitken K, Allen L, Pantazi S, Kingdom J, Keating S, Pollard L, et al. MRI significantly improves disease staging to direct surgical planning for abnormal invasive placentation: a single centre experience. J Obstet Gynaecol Can. 2016;38:246-51.

31. Kumar I, Verma A, Ojha R, Shukla RC, Jain M, Srivastava A. Invasive placental disorders: a prospective US and MRI comparative analysis. Acta Radiol. 2017;58:121-8.

32. Bour L, Placè V, Bendavid S, Fargeaudou Y, Portal JJ, Ricbourg A, et al. Suspected invasive placenta: evaluation with magnetic resonance imaging. Eur Radiol. 2014;24:3150-60.

33. Algebally AM, Yousef RR, Badr SS, Al Obeidly A, Szmigielski W, Al Ibrahim AA. The value of ultrasound and magnetic resonance imaging in diagnostics and prediction of morbidity in cases of placenta previa with abnormal placentation. Pol J Radiol. 2014;79:409-16.
34. Alamo L, Anaye A, Rey J, Denys A, Bongartz G, Terraz S, et al. Detection of suspected placental invasion by MRI: do the results depend on observer' experience? Eur J Radiol. 2013;82:e51-7.

35. Lim PS, Greenberg M, Edelson MI, Bell KA, Edmonds PR, Mackey AM. Utility of ultrasound and mri in prenatal diagnosis of placenta accreta: a pilot study. AJR Am J Roentgenol. 2011;197:1506-13.

36. Derman AY, Nikac V, Heberman S, Zelenko N, Opsha O, Flyer M. MRI of placenta accreta: a new imaging perspective. AJR Am J Roentgenol. 2011;197:1514-21.

37. Teo TH, Law YM, Tay KH, Tan BS, Cheah FK. Use of magnetic resonance imaging in evaluation of placental invasion. Clin Radiol. 2009;64:511-8.

38. Masselli G, Brunelli R, Casciani E, Polettini E, Piccioni MG, Anceschi M, et al. Magnetic resonance imaging in the evaluation of placental adhesive disorders: correlation with color Doppler ultrasound. Eur Radiol. 2008;18:1292-9.

39. Kim JA, Narra VR. Magnetic resonance imaging with true fast imaging with steady-state precession and half-Fourier acquisition single-shot turbo spin-echo sequences in cases of suspected placenta accreta. Acta Radiol. 2004;45:692-8.

40. Rac MW, Dashe JS, Wells CE, Moschos E, McIntire DD, Twickler DM. Ultrasound predictors of placental invasion: the Placenta Accreta Index. Am J Obstet Gynecol. 2015;212:343.e1-7.

41. Pagani G, Cali G, Acharya G, Timor Trisch I, PalaciosJaraquemada J, Familiari A, et al. Diagnostic accuracy of ultrasound in detecting the severity of abnormally invasive placentation: a systematic review and meta-analysis. Acta Obstet Gynecol Scand. 2017; https://doi.org/10.1111/aogs. 13238

\section{Supporting information}

Additional Supporting Information may be found in the online version of this article:

Table S1. Search strategy.

Table S2. Excluded studies and reason for the exclusion.

Table S3. Results of the meta-analyses evaluating the association between each selected MRI sign and each degree of placental invasion.

Table S4. Pooled rates of: (A) placenta accreta; (B) placenta increta; (C) placenta accreta+increta; (D) placenta percreta in pregnancies with (left) and without (right) each MRI sign. Data from single studies have been combined using proportion meta-analysis (random-effect model). CI, confidence interval. 
Supporting Information 1. Search strategy.

\section{EMBASE}

1 exp Placenta Accreta/ (3080)

2 (placenta* adj5 accreta*).tw. (1988)

3 (placenta* adj5 increta*).tw. (470)

4 (placenta* adj5 percreta*).tw. (907)

5 (invas* adj5 placenta*).tw. (1714)

6 (infiltrat* adj5 placenta*).tw. (230)

7 (placenta* adj5 adhes*).tw. (270)

8 (adhere* adj5 placenta*).tw. (692)

9 "myometrial invasion*".tw. (2876)

10 (myometri* adj5 (invad* or invasion*)).tw. (3408)

11 "Morbidly adherent placenta".tw. (213)

12 (Morbid* adhere* adj5 placenta*).tw. (260)

13 "Abnormal invasive placenta".tw. (5)

14 (Abnorm* adj5 invasi* adj5 placenta*).tw. (177)

151 or 2 or 3 or 4 or 5 or 6 or 7 or 8 or 9 or 10 or 11 or 12 or 13 or 14 (8930)

16 exp Ultrasonography/ (633694)

17 (ultrasound* or ultrasonograph*).tw. (382563)

18 endosonograph*.tw. (3473)

19 sonograph*.tw. (64372)

20 MRI*.tw. (305042)

21 exp Magnetic Resonance Imaging/ (748839)

22 "magnetic resonance imag*".tw. (222840)

23 (image* or imaging).tw. (1176661)

24 exp Diagnostic Imaging/ (139764)

25 (echoplanar adj5 imag*).tw. (446)

26 ("echo planar" adj5 imag*).tw. (3732)

27 ("echo-planar" adj5 imag*).tw. (3732)

28 (doppler or USS).tw. (129906)

29 echograph*.tw. (11634)

30 screen*.tw. (791632)

31 exp Mass Screening/ (204355)

3216 or 17 or 18 or 19 or 20 or 21 or 22 or 23 or 24 or 25 or 26 or 27 or 28 or 29 or 30 or

$31(2998350)$

33 exp Prenatal Diagnosis/ (95324)

34 (antenatal* or "ante natal*").tw. (41149)

35 (prenatal* or "pre natal*").tw. (104498)

36 ((before or prior or preced*) adj5 (birth* or born or labour or labor or parturi*)).tw.

(22412)

3733 or 34 or 35 or $36(213157)$

$38 \quad 15$ and 32 and 37 (534)

39 limit 38 to english language (496) 


\section{MEDLINE}

$$
\begin{array}{ll}
1 & \text { exp Placenta Accreta/ (1704) } \\
2 & \text { (placenta* adj5 accreta*).tw. (1413) } \\
3 & \text { (placenta* adj5 increta*).tw. (307) } \\
4 & \text { (placenta* adj5 percreta*).tw. (610) } \\
5 & \text { (invas* adj5 placenta*).tw. (1110) } \\
6 & \text { (infiltrat* adj5 placenta*).tw. (170) } \\
7 & \text { (placenta* adj5 adhes*).tw. (204) } \\
8 & \text { (adhere* adj5 placenta*).tw. (420) } \\
9 & \text { "myometrial invasion*".tw. (1983) }
\end{array}
$$

10 (myometri* adj5 (invad* or invasion*)).tw. (2345)

11 "Morbidly adherent placenta".tw. (107)

12 (Morbid* adhere* adj5 placenta*).tw. (131)

13 "Abnormal invasive placenta".tw. (1)

14 (Abnorm* adj5 invasi* adj5 placenta*).tw. (107)

151 or 2 or 3 or 4 or 5 or 6 or 7 or 8 or 9 or 10 or 11 or 12 or 13 or 14 (6038)

16 exp Ultrasonography/ (379729)

17 (ultrasound* or ultrasonograph*).tw. (263531)

18 endosonograph*.tw. (2376)

19 sonograph*.tw. (48240)

20 MRI*.tw. (180780)

21 exp Magnetic Resonance Imaging/ (365559)

22 "magnetic resonance imag*".tw. (177248)

23 (image* or imaging).tw. (880455)

24 exp Diagnostic Imaging/ (2331532)

25 (echoplanar adj5 imag*).tw. (317)

26 ("echo planar" adj5 imag*).tw. (3016)

27 ("echo-planar" adj5 imag*).tw. (3016)

28 (doppler or USS).tw. (91665)

29 echograph*.tw. (9061)

30 screen*.tw. (574359)

31 exp Mass Screening/ (111739)

3216 or 17 or 18 or 19 or 20 or 21 or 22 or 23 or 24 or 25 or 26 or 27 or 28 or 29 or 30 or 31 (3348031)

33 exp Prenatal Diagnosis/ (66466)

34 (antenatal* or "ante natal*").tw. (30102)

35 (prenatal* or "pre natal*").tw. (83174)

36 ((before or prior or preced*) adj5 (birth* or born or labour or labor or parturi*)).tw. (17934)

3733 or 34 or 35 or $36(161379)$

$38 \quad 15$ and 32 and 37 (366)

39 limit 38 to english language (328) 
1. CINAHL; PLACENTA ACCRETA/;

3. CINAHL; (placenta* N5 accreta*).ti,ab;

4. CINAHL; (placenta* N5 increta*).ti,ab;

5. CINAHL; (placenta* N5 percreta*).ti,ab;

6. CINAHL; (invas* N5 placenta*).ti,ab;

7. CINAHL; (infiltrat* N5 placenta*).ti,ab;

8. CINAHL; (adhere* N5 placenta*).ti,ab;

9. CINAHL; (Morbid* adhere* adj5 placenta*).ti, ab;

10. CINAHL; (Abnorm* adj5 invasi* adj5 placenta). ti, ab;

11. CINAHL; "myometrial invasion*".ti,ab;.

12. CINAHL; (myometri* N5 (invad* OR invasion*)).ti,ab;.

13. CINAHL; 1 OR 3 OR 4 OR 5 OR 6 OR 7 OR 8 OR 9 OR 10;

14. CINAHL; exp ULTRASONOGRAPHY/;

15. CINAHL; (ultrasound* OR ultrasonograph*).ti,ab;

16. CINAHL; endosonograph*.ti,ab;

17. CINAHL; sonograph*.ti,ab;

18. CINAHL; MRI*.ti,ab; 8960 results.

19. CINAHL; exp MAGNETIC RESONANCE IMAGING/;

20. CINAHL; "magnetic resonance imag*".ti,ab;

21. CINAHL; (image* OR imaging).ti,ab;

22. CINAHL; exp DIAGNOSTIC IMAGING/;

23. CINAHL; (echoplanar N5 imag*).ti,ab;

24. CINAHL; ("echo planar" N5 imag*).ti,ab;

25. CINAHL; ("echo-planar" N5 imag*).ti,ab;

26. CINAHL; (doppler OR USS).ti,ab;

27. CINAHL; echograph*.ti,ab;

28. CINAHL; screen*.ti,ab;

29. CINAHL; 12 OR 13 OR 14 OR 15 OR 16 OR 17 OR 18 OR 19 OR 20 OR 21 OR 22 OR 23 OR 24 OR 25 OR 26;

30. CINAHL; exp PRENATAL DIAGNOSIS/;

31. CINAHL; (antenatal* OR "ante natal*").ti,ab;

31. CINAHL; (prenatal* OR "pre natal*").ti,ab;

33. CINAHL; ((before OR prior OR preced*) adj5 (birth* OR born OR labour OR labor OR parturi*)).ti,ab;

34. CINAHL; 28 OR 29 OR 30 OR 31;

35. CINAHL; 11 AND 27 AND 32;

36. CINAHL; 33 [Limit to: Publication Year 1990-2013 and (Language English)]; 


\section{Cochrane}

\#1 MeSH descriptor: [Placenta Accreta] 13

\#2 placenta* near/5 accreta*:ti,ab,kw 40

\#3 placenta* near/5 (increta* or percreta*):ti,ab,kw 9

\#4 invas* near/5 placenta*:ti,ab,kw 15

\#5 infiltrat* near/5 placenta*:ti,ab,kw 4

\#6 Morbid* adhere* near/5 placenta*:ti,ab,kw 5

\#7 Abnorm* near/5 invasi* near/5 placenta*:ti,ab,kw 1

\#8 placenta* near/5 adhes*:ti,ab,kw 5

\#9 adhere* near/5 placenta*:ti,ab,kw 13

\#10 "myometrial invasion*":ti,ab,kw 59

\#11 (myometri* near/5 (invad* or invasion*)):ti,ab,kw 61

$\# 12 \# 1$ or \#2 or \#3 or \#4 or \#5 or \#6 or \#7 or \#8 or \#9 or \#10 or \#11 
Supporting Information 2: Excluded studies and reason for the exclusion.

\begin{tabular}{|c|c|c|c|}
\hline Author & Year & Title & Reason for the exclusion \\
\hline Millischer & 2017 & $\begin{array}{l}\text { Dynamic contrast enhanced MRI of the placenta: A tool for prenatal diagnosis of placenta } \\
\text { accreta? }\end{array}$ & $\begin{array}{l}\text { It was not possible to extrapolate any data regarding the diagnostic } \\
\text { accuracy of MRI in detecting the severity of AIP }\end{array}$ \\
\hline Lim & 2016 & $\begin{array}{c}\text { Correlation of probability scores of placenta accreta on magnetic resonance imaging with } \\
\text { hemorrhagic morbidity }\end{array}$ & $\begin{array}{l}\text { It was not possible to extrapolate any data regarding the diagnostic } \\
\text { accuracy of MRI in detecting the severity of AIP }\end{array}$ \\
\hline Millischer & 2016 & $\begin{array}{l}\text { Magnetic resonance imaging for abnormally invasive placenta: the added value of } \\
\text { intravenous gadolinium injection }\end{array}$ & $\begin{array}{l}\text { It was not possible to extrapolate any data regarding the diagnostic } \\
\text { accuracy of MRI in detecting the severity of AIP }\end{array}$ \\
\hline Ueno & 2016 & $\begin{array}{c}\text { Evaluation of Interobserver Variability and Diagnostic Performance of Developed MRI- } \\
\text { Based Radiological Scoring System for Invasive Placenta Previa }\end{array}$ & $\begin{array}{l}\text { It was not possible to extrapolate any data regarding the diagnostic } \\
\text { accuracy of MRI in detecting the severity of AIP }\end{array}$ \\
\hline Kelekci & 2015 & $\begin{array}{c}\text { A Comprehensive Surgical Procedure in Conservative Management of Placenta Accreta A } \\
\text { Case Series }\end{array}$ & $\begin{array}{l}\text { It was not possible to extrapolate the data regarding the diagnostic } \\
\text { performance of MRI and related MRI signs in detecting the severity of } \\
\text { placental invasion }\end{array}$ \\
\hline Salim & 2015 & Precesarean Prophylactic Balloon Catheters for Suspected Placenta Accreta & No data on diagnostic accuracy of MRI in detecting the severity of AIP \\
\hline Lyell & 2015 & $\begin{array}{c}\text { Maternal serum markers, characteristics and morbidly adherent placenta in women with } \\
\text { previa }\end{array}$ & No data on diagnostic accuracy of MRI in detecting the severity of AIP \\
\hline Tanimura & 2015 & $\begin{array}{c}\text { Prediction of adherent placenta in pregnancy with placenta previa using ultrasonography } \\
\text { and magnetic resonance imaging }\end{array}$ & No data on diagnostic accuracy of MRI in detecting the severity of AIP \\
\hline Kumar & 2015 & $\begin{array}{c}\text { Chemical Shift Artifact on Steady-State MRI Sequences for Detection of Vesical Wall } \\
\text { Invasion in Placenta Percreta }\end{array}$ & $\begin{array}{l}\text { This study shares cases with that of Kumar et al. Whihc has been } \\
\text { included in the present systematic as the most representative from this } \\
\text { group }\end{array}$ \\
\hline Horowitz & 2015 & $\begin{array}{l}\text { When Timing Is Everything: Are Placental MRI Examinations Performed Before } 24 \\
\text { Weeks' Gestational Age Reliable? }\end{array}$ & $\begin{array}{l}\text { It was not possible to extrapolate any data regarding the diagnostic } \\
\text { accuracy of MRI in detecting the severity of AIP }\end{array}$ \\
\hline Alchalabi & 2014 & $\begin{array}{l}\text { Morbidly adherent placenta previa in current practice: prediction and maternal morbidity } \\
\text { in a series of } 23 \text { women who underwent hysterectomy }\end{array}$ & $\begin{array}{l}\text { It was not possible to extrapolate the data regarding the diagnostic } \\
\text { performance of MRI and related MRI signs in detecting the severity of } \\
\text { placental invasion }\end{array}$ \\
\hline Rezk & 2014 & $\begin{array}{c}\text { Grey-scale and colour Doppler ultrasound versus magnetic resonance imaging for the } \\
\text { prenatal diagnosis of placenta accreta }\end{array}$ & No data on diagnostic accuracy of MRI in detecting the severity of AIP \\
\hline Riteau & 2014 & $\begin{array}{c}\text { Accuracy of Ultrasonography and Magnetic Resonance Imaging in the Diagnosis of } \\
\text { Placenta Accreta }\end{array}$ & No data on diagnostic accuracy of MRI in detecting the severity of AIP \\
\hline Noda & 2014 & Prenatal MR imaging diagnosis of placental invasion & $\begin{array}{l}\text { It was not possible to extrapolate any data regarding the diagnostic } \\
\text { accuracy of MRI in detecting the severity of AIP }\end{array}$ \\
\hline
\end{tabular}




\begin{tabular}{|c|c|c|c|}
\hline Ueno & 2014 & $\begin{array}{l}\text { Novel MRI finding for diagnosis of invasive placenta praevia: evaluation of findings for } \\
65 \text { patients using clinical and histopathological correlations }\end{array}$ & $\begin{array}{l}\text { It was not possible to extrapolate any data regarding the diagnostic } \\
\text { accuracy of MRI in detecting the severity of AIP }\end{array}$ \\
\hline Peker & 2013 & $\begin{array}{l}\text { Assessment of total placenta previa by magnetic resonance imaging and ultrasonography } \\
\text { to detect placenta accreta and its variants }\end{array}$ & $\begin{array}{l}\text { It was not possible to extrapolate the data regarding the diagnostic } \\
\text { performance of MRI and related MRI signs in detecting the severity of } \\
\text { placental invasion }\end{array}$ \\
\hline Salomon & 2013 & MRI and ultrasound fusion imaging for prenatal diagnosis & Only 1 case of AIP included in this series \\
\hline Maher & 2013 & Diagnostic accuracy of ultrasound and MRI in the prenatal diagnosis of placenta accreta & No data on diagnostic accuracy of MRI in detecting the severity of AIP \\
\hline Elhawary & 2013 & $\begin{array}{l}\text { Diagnostic value of ultrasonography and magnetic resonance imaging in pregnant women } \\
\text { at risk for placenta accreta }\end{array}$ & The generic term accreta was used to label any type of AIP \\
\hline Fitzpatrick & 2012 & $\begin{array}{c}\text { Incidence and Risk Factors for Placenta Accreta/Increta/ Percreta in the UK: A National } \\
\text { Case-Control Study }\end{array}$ & No data on diagnostic accuracy of MRI in detecting the severity of AIP \\
\hline Shweel & 2012 & $\begin{array}{c}\text { Placenta accreta in women with prior uterine surgery: Diagnostic accuracy of Doppler } \\
\text { ultrasonography and MRI }\end{array}$ & $\begin{array}{l}\text { The generic term "accreta" was used to label all types of AIP; it was } \\
\text { not possible to evaluate the diagnostic accuracy of MRI in detecting } \\
\text { the severity of AIP }\end{array}$ \\
\hline Sadashivaiah & 2011 & $\begin{array}{l}\text { Role of prophylactic uterine artery balloon catheters in the management of women with } \\
\text { suspected placenta accreta }\end{array}$ & No data on diagnostic accuracy of MRI in detecting the severity of AIP \\
\hline Mansour & 2011 & Placenta previa - accreta: Do we need MR imaging? & $\begin{array}{l}\text { It was not stated the number of placenta accreta, increta and percreta, } \\
\text { so it was not possible to extrapolate any data regarding the diagnostic } \\
\text { accuracy of MRI in detecting the severity of AIP }\end{array}$ \\
\hline McLean & 2011 & $\begin{array}{c}\text { Assessing the Role of Magnetic Resonance Imaging in the Management of Gravid } \\
\text { Patients at Risk for Placenta Accreta }\end{array}$ & $\begin{array}{l}\text { It was not possible to extrapolate any data regarding the diagnostic } \\
\text { accuracy of MRI in detecting the severity of AIP }\end{array}$ \\
\hline Carnevale & 2011 & $\begin{array}{l}\text { Perioperative Temporary Occlusion of the Internal Iliac Arteries as Prophylaxis in } \\
\text { Cesarean Section at Risk of Hemorrhage in Placenta Accreta }\end{array}$ & $\begin{array}{l}\text { No true and false negative cases were included in this series, thus it } \\
\text { was not possible to calculate all the figures for diagnostic accuracy }\end{array}$ \\
\hline Tamaka & 2011 & High temporal resolution dynamic contrast MRI in a high risk group for placenta accreta & The generic term accreta was used to label any type of AIP \\
\hline Mazouni & 2009 & $\begin{array}{c}\text { Differences in the management of suspected cases of placenta accreta in France and } \\
\text { Argentina }\end{array}$ & $\begin{array}{l}\text { Only cases diagnosed prenatally included in this study; furthermore, it } \\
\text { was not possible to extrapolate any data regarding the diagnostic } \\
\text { accuracy of MRI in detecting the severity of AIP }\end{array}$ \\
\hline Dwyer & 2008 & Prenatal Diagnosis of Placenta Accreta Sonography or Magnetic Resonance Imaging? & The generic term accreta was used to label any type of AIP \\
\hline Lax & 2007 & The value of specific MRI features in the evaluation of suspected placental invasion & $\begin{array}{l}\text { It was not possible to extrapolate any data regarding the diagnostic } \\
\text { accuracy of MRI in detecting the severity of AIP }\end{array}$ \\
\hline Warshack & 2006 & $\begin{array}{c}\text { Accuracy of Ultrasonography and Magnetic Resonance Imaging in the Diagnosis of } \\
\text { Placenta Accreta }\end{array}$ & $\begin{array}{l}\text { The generic term "accreta" was used to label all types of AIP; it was } \\
\text { not possible to evaluate the diagnostic accuracy of MRI in detecting } \\
\text { the severity of AIP }\end{array}$ \\
\hline
\end{tabular}




\section{$\mathrm{Wu}$}

Moodley

Lam

Stolpen
2005

2004

2002

2001
Abnormal placentation: Twenty-year analysis

Imaging techniques to identify morbidly adherent placenta praevia: a prospective study

Use of magnetic resonance imaging and ultrasound in the antenatal diagnosis of placenta

accreta

Antepartum Evaluation of Suspected Placenta Accreta: Is there a role for MRI?
No data on diagnostic accuracy of MRI in detecting the severity of AIP

The generic term accreta was used to label any type of AIP

No data on the diagnostic accuracy of ultrasound in detecting the severity of AIP

Less than 5 cases included 
Table S3. Results of the meta-analyses evaluating the association between each selected MRI sign and each degree of placental invasion.

\begin{tabular}{|c|c|c|c|c|c|c|c|c|c|c|c|c|}
\hline & \multicolumn{3}{|c|}{ A. Placenta accreta } & \multicolumn{3}{|c|}{ B. Placenta increta } & \multicolumn{3}{|c|}{ C. Placenta accreta + increta } & \multicolumn{3}{|c|}{ D. Placenta percreta } \\
\hline MRI sign & $\begin{array}{c}\text { N. studies } \\
\text { (total sample) }\end{array}$ & Raw data* & $\begin{array}{c}\text { Pooled OR } \\
(95 \% \mathrm{CI})\end{array}$ & $\begin{array}{c}\text { N. studies } \\
\text { (total sample) }\end{array}$ & Raw data* & $\begin{array}{c}\text { Pooled OR } \\
(95 \% \mathrm{CI})\end{array}$ & $\begin{array}{c}\text { N. studies } \\
\text { (total sample) }\end{array}$ & Raw data* & $\begin{array}{c}\begin{array}{c}\text { Pooled OR } \\
(95 \% \mathrm{CI})\end{array} \\
\end{array}$ & $\begin{array}{c}\text { N. studies } \\
\text { (total sample) }\end{array}$ & $\begin{array}{l}\text { Raw } \\
\text { data* }\end{array}$ & $\begin{array}{c}\begin{array}{c}\text { Pooled OR } \\
(95 \% \text { CI })\end{array} \\
\end{array}$ \\
\hline $\begin{array}{c}1 . \\
\text { Intraplacental dark } \\
\text { bands }\end{array}$ & $\begin{array}{c}7 \\
(170)\end{array}$ & $\begin{array}{l}19 / 81 \\
\text { vs } \\
5 / 89\end{array}$ & $\begin{array}{c}5.15 \\
(1.82-14.5)\end{array}$ & $\begin{array}{c}6 \\
(163)\end{array}$ & $\begin{array}{c}26 / 75 \\
\text { vs } \\
3 / 88\end{array}$ & $\begin{array}{c}15.0 \\
(4.33-52.2)\end{array}$ & $\begin{array}{c}9 \\
(240)\end{array}$ & $\begin{array}{l}59 / 110 \\
\text { vs } \\
16 / 130\end{array}$ & $\begin{array}{c}8.24 \\
(4.33-15.7)\end{array}$ & $\begin{array}{c}9 \\
(241)\end{array}$ & $\begin{array}{l}38 / 110 \\
\text { vs } \\
8 / 131\end{array}$ & $\begin{array}{c}7.94 \\
(3.19-19.8)\end{array}$ \\
\hline $\begin{array}{c}2 . \\
\text { Uterine bulging }\end{array}$ & $\begin{array}{c}6 \\
(153)\end{array}$ & $\begin{array}{l}12 / 66 \\
\text { vs } \\
10 / 87\end{array}$ & $\begin{array}{c}1.71 \\
(0.69-4.24)\end{array}$ & $\begin{array}{c}5 \\
(146)\end{array}$ & $\begin{array}{l}21 / 60 \\
\text { vs } \\
7 / 86\end{array}$ & $\begin{array}{c}6.08 \\
(2.38-15.5)\end{array}$ & $\begin{array}{c}8 \\
(224)\end{array}$ & $\begin{array}{l}44 / 92 \\
\text { vs } \\
28 / 132\end{array}$ & $\begin{array}{c}3.49 \\
(1.90-6.38)\end{array}$ & $\begin{array}{c}8 \\
(224)\end{array}$ & $\begin{array}{c}35 / 92 \\
\text { vs } \\
10 / 132\end{array}$ & $\begin{array}{c}6.26 \\
(2.71-14.4)\end{array}$ \\
\hline $\begin{array}{c}3 . \\
\text { Heterogeneous placental } \\
\text { signal intensity }\end{array}$ & $\begin{array}{c}4 \\
(94)\end{array}$ & $\begin{array}{l}9 / 37 \\
\text { vs } \\
3 / 57\end{array}$ & $\begin{array}{c}5.79 \\
(1.45-23.1)\end{array}$ & $\begin{array}{c}3 \\
(87)\end{array}$ & $\begin{array}{l}9 / 31 \\
\text { vs } \\
2 / 56\end{array}$ & $\begin{array}{c}16.5 \\
(2.81-97.0)\end{array}$ & $\begin{array}{c}6 \\
(165)\end{array}$ & $\begin{array}{l}35 / 73 \\
\text { vs } \\
10 / 92\end{array}$ & $\begin{array}{c}7.85 \\
(3.39-18.2)\end{array}$ & $\begin{array}{c}6 \\
(165)\end{array}$ & $\begin{array}{l}20 / 73 \\
\text { vs } \\
8 / 92\end{array}$ & $\begin{array}{c}3.52 \\
(1.34-9.30)\end{array}$ \\
\hline $\begin{array}{c}4 . \\
\text { Focal myometrial } \\
\text { interruption }\end{array}$ & $\begin{array}{c}5 \\
(130)\end{array}$ & $\begin{array}{l}14 / 44 \\
\text { vs } \\
8 / 86\end{array}$ & $\begin{array}{c}4.38 \\
(1.63-11.8)\end{array}$ & $\begin{array}{c}4 \\
(125)\end{array}$ & $\begin{array}{c}15 / 41 \\
\text { vs } \\
6 / 84\end{array}$ & $\begin{array}{c}7.50 \\
(2.64-21.3)\end{array}$ & $\begin{array}{c}7 \\
(201)\end{array}$ & $\begin{array}{l}44 / 75 \\
\text { vs } \\
21 / 126\end{array}$ & $\begin{array}{c}7.45 \\
(3.77-14.7)\end{array}$ & $\begin{array}{c}6 \\
(196)\end{array}$ & $\begin{array}{c}22 / 72 \\
\text { vs } \\
6 / 124\end{array}$ & $\begin{array}{c}8.71 \\
(3.24-23.4)\end{array}$ \\
\hline $\begin{array}{c}5 . \\
\text { Bladder tenting }\end{array}$ & $\begin{array}{c}2 \\
(48)\end{array}$ & $\begin{array}{l}3 / 13 \\
\text { vs } \\
4 / 35\end{array}$ & $\begin{array}{c}2.32 \\
(0.44-12.2)\end{array}$ & $\begin{array}{c}2 \\
(48)\end{array}$ & $\begin{array}{c}3 / 13 \\
\text { vs } \\
6 / 35\end{array}$ & $\begin{array}{c}1.14 \\
(0.22-6.02)\end{array}$ & $\begin{array}{c}3 \\
(80)\end{array}$ & $\begin{array}{l}6 / 16 \\
\text { vs } \\
20 / 64\end{array}$ & $\begin{array}{c}1.32 \\
(0.42-4.14)\end{array}$ & $\begin{array}{c}3 \\
(80)\end{array}$ & $\begin{array}{l}10 / 16 \\
\text { vs } \\
9 / 64\end{array}$ & $\begin{array}{c}12.8 \\
(2.65-61.4)\end{array}$ \\
\hline $\begin{array}{c}6 . \\
\text { Abnormal intraplacental } \\
\text { vascularity }\end{array}$ & $\begin{array}{c}5 \\
(150)\end{array}$ & $\begin{array}{c}10 / 39 \\
\text { vs } \\
8 / 111\end{array}$ & $\begin{array}{c}4.44 \\
(1.61-12.3)\end{array}$ & $\begin{array}{c}5 \\
(150)\end{array}$ & $\begin{array}{l}12 / 39 \\
\text { vs } \\
14 / 111\end{array}$ & $\begin{array}{c}3.21 \\
(1.28-8.08)\end{array}$ & $\begin{array}{c}6 \\
(182)\end{array}$ & $\begin{array}{l}22 / 47 \\
\text { vs } \\
28 / 135\end{array}$ & $\begin{array}{c}3.36 \\
(1.66-6.82)\end{array}$ & $\begin{array}{c}6 \\
(182)\end{array}$ & $\begin{array}{c}14 / 47 \\
\text { vs } \\
17 / 135\end{array}$ & $\begin{array}{c}3.99 \\
(1.51-10.5)\end{array}$ \\
\hline $\begin{array}{c}7 . \\
\begin{array}{c}\text { Direct invasion/focal } \\
\text { exophitic mass }\end{array}{ }^{\dagger}\end{array}$ & -- & -- & -- & -- & -- & -- & -- & -- & -- & $\begin{array}{c}5 \\
\text { (114) }\end{array}$ & $\begin{array}{c}21 / 24 \\
\text { vs } \\
12 / 90\end{array}$ & $\begin{array}{c}278 \\
(15.3-5036)\end{array}$ \\
\hline
\end{tabular}

* Number of events / Total n. of subjects in the exposed group (i.e. presence of intraplacental dark bands) versus Number of events / Total n. of subjects in the unexposed group (i.e. absence of intraplacental dark bands).

$\mathrm{OR}=$ Odds ratio. $\mathrm{CI}=$ Confidence Interval .

${ }^{\dagger}$ Only placenta percreta. 
Table S4. Pooled rates of: (A) placenta accreta; (B) placenta increta; (C) placenta accreta+increta; (D) placenta percreta in pregnancies with (left) and without (right) each MRI sign. Data from single studies have been combined using proportion meta-analysis (random-effect model). CI = Confidence Interval.

\begin{tabular}{|c|c|c|c|c|c|c|c|c|}
\hline & A. Accreta & B. Increta & C. Accreta+increta & D. Percreta & A. Accreta & B. Increta & C. Accreta+increta & D. Percreta \\
\hline \multirow[t]{2}{*}{$\begin{array}{l}\text { N. studies } \\
\text { A, B, C, D }\end{array}$} & $\begin{array}{l}\text { Pooled \% } \\
\text { (95\% CI) }\end{array}$ & $\begin{array}{l}\text { Pooled \% } \\
(95 \% \text { CI) }\end{array}$ & $\begin{array}{l}\text { Pooled \% } \\
(95 \% \text { CI) }\end{array}$ & $\begin{array}{l}\text { Pooled \% } \\
\text { (95\% CI) }\end{array}$ & $\begin{array}{l}\text { Pooled \% } \\
\text { (95\% CI) }\end{array}$ & $\begin{array}{l}\text { Pooled \% } \\
(95 \% \text { CI) }\end{array}$ & $\begin{array}{l}\text { Pooled \% } \\
(95 \% \text { CI) }\end{array}$ & $\begin{array}{l}\text { Pooled \% } \\
(95 \% \text { CI) }\end{array}$ \\
\hline & \multicolumn{4}{|c|}{ Intraplacental dark bands } & \multicolumn{4}{|c|}{ Absence of intraplacental dark bands } \\
\hline \multirow[t]{2}{*}{$7,6,9,9$} & $\begin{array}{c}23.0 \\
(11.2-36.9)\end{array}$ & $\begin{array}{c}34.2 \\
(23.1-46.1)\end{array}$ & $\begin{array}{c}52.6 \\
(37.2-67.9)\end{array}$ & $\begin{array}{c}33.8 \\
(17.0-52.5)\end{array}$ & $\begin{array}{c}0.4 \\
(0.0-5.7)\end{array}$ & $\begin{array}{c}0.2 \\
(0.0-4.6)\end{array}$ & $\begin{array}{c}6.3 \\
(1.4-13.2) \\
\end{array}$ & $\begin{array}{c}0.5 \\
(0.0-6.8)\end{array}$ \\
\hline & \multicolumn{4}{|c|}{ Uterine bulging } & \multicolumn{4}{|c|}{ Absence of uterine bulging } \\
\hline \multirow[t]{2}{*}{$6,5,8,8$} & $\begin{array}{c}17.0 \\
(6.9-29.6) \\
\end{array}$ & $\begin{array}{c}34.7 \\
(22.4-48.0) \\
\end{array}$ & $\begin{array}{c}47.7 \\
(36.2-59.4) \\
\end{array}$ & $\begin{array}{c}36.2 \\
(20.5-53.4) \\
\end{array}$ & $\begin{array}{c}5.2 \\
(0.2-13.7) \\
\end{array}$ & $\begin{array}{c}4.7 \\
(0.1-13.1) \\
\end{array}$ & $\begin{array}{c}17.1 \\
(8.2-27.5) \\
\end{array}$ & $\begin{array}{c}2.3 \\
(0.0-12.8) \\
\end{array}$ \\
\hline & \multicolumn{4}{|c|}{ Heterogeneous placental signal intensity } & \multicolumn{4}{|c|}{ Homogeneous placental signal intensity } \\
\hline \multirow[t]{2}{*}{$4,3,6,6$} & $\begin{array}{c}23.1 \\
(9.1-40.0)\end{array}$ & $\begin{array}{c}28.6 \\
(4.4-60.1)\end{array}$ & $\begin{array}{c}44.2 \\
(17.8-72.3)\end{array}$ & $\begin{array}{c}26.9 \\
(4.7-56.1)\end{array}$ & $\begin{array}{c}0.2 \\
(0.0-6.8)\end{array}$ & $\begin{array}{c}2.1 \\
(0.0-9.1)\end{array}$ & $\begin{array}{c}4.7 \\
(0.0-15.2)\end{array}$ & $\begin{array}{c}2.6 \\
(0.0-10.9)\end{array}$ \\
\hline & \multicolumn{4}{|c|}{ Focal myometrial interruption } & \multicolumn{4}{|c|}{ Absence of focal myometrial interruption } \\
\hline \multirow[t]{3}{*}{$5,4,7,6$} & $\begin{array}{c}37.7 \\
(10.7-68.6)\end{array}$ & $\begin{array}{c}36.0 \\
(21.0-52.3)\end{array}$ & $\begin{array}{c}61.7 \\
(44.7-77.6) \\
\end{array}$ & $\begin{array}{c}27.5 \\
(11.8-46.0)\end{array}$ & $\begin{array}{c}4.9 \\
(0.0-15.4)\end{array}$ & $\begin{array}{c}5.4 \\
(0.7-12.5)\end{array}$ & $\begin{array}{c}12.8 \\
(4.0-24.4)\end{array}$ & $\begin{array}{c}3.5 \\
(0.4-8.3)\end{array}$ \\
\hline & & & & & & & & \\
\hline & \multicolumn{4}{|c|}{ Bladder tenting } & \multicolumn{4}{|c|}{ Absence of bladder tenting } \\
\hline \multirow[t]{2}{*}{$2,2,3,3$} & $\begin{array}{c}21.7 \\
(1.8-50.4)\end{array}$ & $\begin{array}{c}21.7 \\
(1.8-50.4)\end{array}$ & $\begin{array}{c}32.7 \\
(0.0-81.0)\end{array}$ & $\begin{array}{c}67.3 \\
(19.0-100)\end{array}$ & $\begin{array}{c}11.2 \\
(20.4-24.7)\end{array}$ & $\begin{array}{c}9.4 \\
(1.1-22.3)\end{array}$ & $\begin{array}{c}31.6 \\
(12.3-54.5)\end{array}$ & $\begin{array}{c}12.7 \\
(0.0-43.1)\end{array}$ \\
\hline & \multicolumn{4}{|c|}{ Abnormal intra-placental vascularity } & \multicolumn{4}{|c|}{ Normal intra-placental vascularity } \\
\hline \multirow[t]{2}{*}{$5,5,6,6$} & $\begin{array}{c}22.8 \\
(9.1-39.4)\end{array}$ & $\begin{array}{c}29.5 \\
(14.3-46.7)\end{array}$ & $\begin{array}{c}45.2 \\
(17.7-74.1) \\
\end{array}$ & $\begin{array}{c}28.3 \\
(6.2-56.1)\end{array}$ & $\begin{array}{c}6.7 \\
(2.2-12.8)\end{array}$ & $\begin{array}{c}9.2 \\
(1.1-22.2) \\
\end{array}$ & $\begin{array}{c}20.0 \\
(12.0-29.2) \\
\end{array}$ & $\begin{array}{c}9.9 \\
(0.7-25.4)\end{array}$ \\
\hline & \multicolumn{4}{|c|}{ Direct invasion/focal exophitic mass } & \multicolumn{4}{|c|}{ Absence of direct invasion/focal exophitic mass } \\
\hline $5 *$ & -- & -- & -- & $\begin{array}{c}94.1 \\
(66.1-100)\end{array}$ & -- & -- & -- & $\begin{array}{c}10.9 \\
(0.0-33.3)\end{array}$ \\
\hline & & & & & & & & \\
\hline
\end{tabular}

* Only placenta percreta. 